\title{
Solar activity impact on the Earth's upper atmosphere
}

Ivan Kutiev ${ }^{1, *}$ Ioanna Tsagouri ${ }^{2}$, Loredana Perrone ${ }^{3}$, Dora Pancheva ${ }^{1}$, Plamen Mukhtarov ${ }^{1}$, Andrei Mikhailov ${ }^{4}$, Jan Lastovicka $^{5}$, Norbert Jakowski ${ }^{6}$, Dalia Buresova ${ }^{5}$, Estefania Blanch ${ }^{7}$, Borislav Andonov ${ }^{1}$, David Altadill ${ }^{7}$, Sergio Magdaleno 9 , Mario Parisi ${ }^{8}$, and Joan Miquel Torta ${ }^{7}$

1 National Institute of Geophysics, Geodesy and Geography, Bulgarian Academy of Sciences, 1113 Sofia, Bulgaria *Corresponding author: e-mail: ivankutiev@yahoo.com

2 Institute for Space Applications and Remote Sensing, National Observatory of Athens, 15236 Mount Penteli, Greece

3 Istituto Nazionale di Geofisica e Vulcanologia, 00143 Rome, Italy

4 Institute of Terrestrial Magnetism, Ionosphere, and Radio Propagation, Russian Academy of Sciences, 142190 Troitsk, Moskovskaya obl., Russia

5 Institute of Atmospheric Physics ASCR, 14131 Prague, Czech Republic

6 Institute of Communications and Navigation, German Aerospace Center, 51147 Cologne, Germany

7 Ebro Observatory, University Ramon Llull, CSIC, E-43520 Roquetes, Spain

8 Dipartimento di Fisica, Università degli Studi di Roma, 00185 Rome, Italy

9 Atmospheric Sounding Station "El Arenosillo", INTA, Huelva, Spain

Received 8 June 2012 / Accepted 5 February 2013

\begin{abstract}
The paper describes results of the studies devoted to the solar activity impact on the Earth's upper atmosphere and ionosphere, conducted within the frame of COST ES0803 Action.

Aim: The aim of the paper is to represent results coming from different research groups in a unified form, aligning their specific topics into the general context of the subject.

Methods: The methods used in the paper are based on data-driven analysis. Specific databases are used for spectrum analysis, empirical modeling, electron density profile reconstruction, and forecasting techniques.

Results: Results are grouped in three sections: Medium- and long-term ionospheric response to the changes in solar and geomagnetic activity, storm-time ionospheric response to the solar and geomagnetic forcing, and modeling and forecasting techniques. Section 1 contains five subsections with results on 27-day response of low-latitude ionosphere to solar extreme-ultraviolet (EUV) radiation, response to the recurrent geomagnetic storms, long-term trends in the upper atmosphere, latitudinal dependence of total electron content on EUV changes, and statistical analysis of ionospheric behavior during prolonged period of solar activity.

Section 2 contains a study of ionospheric variations induced by recurrent CIR-driven storm, a case-study of polar cap absorption due to an intense CME, and a statistical study of geographic distribution of so-called E-layer dominated ionosphere.

Section 3 comprises empirical models for describing and forecasting TEC, the F-layer critical frequency $f_{o} F 2$, and the height of maximum plasma density. A study evaluates the usefulness of effective sunspot number in specifying the ionosphere state. An original method is presented, which retrieves the basic thermospheric parameters from ionospheric sounding data.
\end{abstract}

Key words. ionosphere - solar activity - storm - total electron content - data analysis

\section{Introduction}

A number of studies have been conducted in the frame of subgroup (SG)1.1 devoted to the solar activity impact on the Earth's upper atmosphere. Response of the thermosphere and ionosphere to the changes of solar activity is important part of the space weather issue, because of its impact on the human space-based activity. The studies cover wide range of contemporary topics identified in the Action's scientific program. The results of the studies can be grouped into three major topics. One is the response of the ionosphere to the periodic changes of solar activity with time scale from several days to a month (medium-term response) and those with time scale of the order of several solar cycles. The second group of topics covers studies on the ionospheric response to geomagnetic storms, which have time scale from several hours to 2-3 days. The third group contains development of empirical models and forecasting techniques, which are aimed to feed the space weather operational services.

\subsection{Medium- and long-term ionospheric response to the changes in solar and geomagnetic activity}

Active regions on the Sun impact the Earth's thermosphere and ionosphere through several different channels. Variability of neutral and ionized density is a net result of the different forcing mechanisms whose individual contributions are difficult to be assessed. One powerful method for statistical identification of the relations between active processes on the Sun, their geophysical consequences and atmospheric variability, is the spectrum analysis. The coherent oscillations of both media at various timescales are used to identify the background physical processes. Quasi-27-day periodicity is a typical medium-term response of the neutral atmosphere and ionosphere to the 
changes in solar and geomagnetic activity. The main factor generating such changes is the repeatable influence of active regions on the Sun's surface which rotate with a period of 27 days. This influence is transmitted to the Earth in two ways: by EUV radiation and by solar wind. It is well accepted that the neutral atmosphere and ionosphere respond collectively to both these solar influences, but the time scales of their responses are still uncertain. The 27-day periodicity in the solar EUV radiation directly impacts the atmospheric temperature and ion production. Since the pioneering works of Maunder (1904) and Bartels (1934), numerous papers were devoted to the solar 27-day periodicity and its effects on the upper atmosphere and ionosphere. Recently, the presence of a 27-day oscillation in the ionosphere has been reported by Altadill et al. (2001), Pancheva et al. (2002), Altadill \& Apostolov (2003), and others.

Solar wind high-speed streams (HSSs) emanated from solar coronal holes cause recurrent, moderate geomagnetic activity, which can last more than one solar rotation (see, e.g., the review of Tsurutani et al. 2006) and therefore induce 27-day variations in the ionosphere. HSSs, when emanated away from the Sun, interact with preceding low-speed solar wind and form a "co-rotating interactive region (CIR)". This interface region between low- and high speed solar plasma produces geomagnetic disturbances when it interacts with the Earth's magnetosphere. Thus, a single coronal hole can produce multiple CIRs if the hole lives longer than one solar rotation. Temmer et al. (2007) compared the variability of coronal holes areas with solar wind data and geomagnetic indices for January-September 2005. Applying wavelet analysis, they found a clear 9-day periodicity in both, coronal hole appearance and solar wind parameters. These authors suggested that these periodic variations are caused by coronal holes distributed roughly $120^{\circ}$ apart in solar longitude. This topology was stable for the first 5 months, followed by a dual coronal hole distribution producing 13.5-day periodic variations up to the end of the observation period. Coronal holes are most prevalent during the declining phase of the solar cycle and can persist for many solar rotations (Borovsky \& Denton 2006; Vršnak et al. 2007). Recently the 9-day variability has been found in the neutral density of the Earth's thermosphere (Lei et al. 2008) and the infrared energy budget of the thermosphere (Mlynczak et al. 2008). Thayer et al. (2008) have shown that the thermospheric mass density response is global and varies coherently with the recurrent geomagnetic activity, although the response is slightly larger at high latitudes. Modifications of the midlatitude $F$ region during persistent HSSs have been studied by Denton et al. (2009). By using superposed epoch analysis, these authors studied changes in F-region parameters before and after the onset of magnetospheric convection, the latter represented by sudden increases of $K p$-index above 4. They found that nighttime peak density decreases consistently with storm onset and gradually recovers to the pre-storm levels in about 4 days. The daytime peak density also exhibits a sharp increase at storm onset, followed by a decrease below the quiet level that again gradually recovers within 3-4 days. As was pointed out above, the main question which recent studies are trying to answer is how the mechanisms generating particular disturbances in atmosphere and ionosphere can be identified. Analysis of the spectral characteristics of the solar forcing and ionospheric response can provide an important clue to the understanding and modeling the physical processes controlling the space weather and space climate in general.
Long-term trends (longer than solar cycle) in the upper atmosphere-ionosphere are a complex problem due to simultaneous presence of several drivers of trends, which behave in a different way: increasing atmospheric concentration of greenhouse gases, mainly $\mathrm{CO}_{2}$, long-term changes of geomagnetic and solar activity, secular change of the Earth's main magnetic field, remarkable long-term changes of stratospheric ozone concentration, and very probably long-term changes of atmospheric dynamics, particularly of atmospheric wave activity (Lastovicka 2009; Qian et al. 2011; Lastovicka et al. 2012). Whereas $\mathrm{CO}_{2}$ concentration is quasi-steadily increasing, other drivers change their trends with time even to opposite (solar and geomagnetic activity, stratospheric ozone), or change trends with location (Earth's main magnetic field), or with latitude (geomagnetic activity), or are largely unknown but probably unstable in space and time (atmospheric winds and waves). Consequently, the trends in the upper atmosphere-ionosphere system cannot be stable; they have to change in time and space (e.g., Lastovicka et al. 2012). Such trends might be represented by piecewise linear trends. Therefore, important question to be answered in the recent studies is how to assess the impact of space weather/climate on long-term trends in the upper atmosphere-ionosphere system.

\subsection{Storm-time ionospheric response to the solar and geomagnetic forcing}

From the active region on the Sun's surface emerges solar particles that can produce geomagnetic disturbances in the Earth's magnetosphere. CME events are usually the origin of intense geomagnetic storm and they occur predominantly during solar maximum phase. Coronal holes emit high-speed solar wind (HSS), capable to produce a series of moderate and weaker geomagnetic storms which continuously (recurrently) appear during periods longer than one solar rotation. The latter storms more frequently appear during declining and solar minimum phases (see, e.g., Borovsky et al. 2006). Extensive studies have recently been conducted in attempt to differentiate the ionospheric response of CME- and CIR-driven storms. On this line, special interest is paid to ionospheric response (ionospheric storms) during the unusually prolonged solar minimum (2006-2009), when the EUV solar irradiance and CME occurrence were very low, but nevertheless moderate and weaker geomagnetic storms frequently took place.

CME-driven geomagnetic storms disturb strongly the magnetosphere. The plasma sheet is overpopulated with energetic particles, the ring current intensifies, strong solar energetic particles appear in the polar caps through the cusp regions. Special interest invokes the so-called polar cap absorption events produced by energetic solar protons emitted in the CME regions on the Sun and accelerated by CME sheaths and magnetic clouds during their travel to the Earth's magnetosphere. During the solar proton events (SPE), the solar energetic protons $(<1 \mathrm{MeV})$ produce abnormal ionization in ionospheric Dregion which absorbs radio waves in the HF and VHF bands. PCA events are regularly studied because they can provide important information about the nature of the SPE and hence information about the generation of CME and acceleration processes in the interplanetary medium. The intensive particle fluxes in the magnetosphere plasma sheet during the CME-driven storms penetrate into the auroral zone and produce the famous auroras. The plasma sheet particles with higher energies penetrate deeper in the atmosphere and produce additional 


\section{Kutiev et al.: Solar activity impact on upper atmosphere}

ionization in the E-layer. Frequently, the plasma density in the E-layer exceeds that in the F-layer (Mayer \& Jakowski 2009), a phenomenon known as E-layer dominated ionosphere (ELDI).

\subsection{Modeling and forecasting techniques}

Ionospheric behavior during geomagnetic storms, the most fascinating subject in the ionospheric physics, has long been studied. Numerous applications connected with ionosphere invoked the necessity of modeling and predicting the ionospheric state. Theoretical modeling using momentum equations for ionospheric plasma has great impact on ionospheric physics, describing and predicting the main properties of the media. For application purposes, however, empirical modeling of ionospheric parameters has been found most suitable and accurate. The modeling approach is based on presenting the ionospheric parameter (most frequently the F-layer critical frequency $f_{o} F 2$ ) by analytical expressions as a function of one or more geomagnetic or solar indices, called drivers. Geomagnetic indices, like $K p$, ap, Dst, etc., better correlate with the short-term changes of ionosphere from several hours to several days (Araujo-Pradere et al. 2002; Muhtarov et al. 2002). Solar indices, like sunspot number R and solar flux F10.7, better suit the long-term variations of the order of months (Bilitza 2000). It is obvious that ionospheric parameters and geomagnetic indices are controlled by the same magnetospheric processes, but geomagnetic indices react faster to magnetospheric changes, while ionosphere response is more delayed. This time delay in reactions (2$3 \mathrm{~h}$ ) is assumed enough to consider the geomagnetic drivers as a forcing and ionosphere as a response to that forcing. Recently, the availability of solar wind parameters and interplanetary magnetic field (IMF) measured outside the magnetosphere (for example, ACE satellite at L1 libration point) made them appropriate for short-term drivers, due to the fact that the travel time from the L1 point (1.5 million $\mathrm{km}$ from the Earth) to the magnetosphere is around half an hour. Forecasting techniques are based on the empirical models with predicted values of the drivers. Empirical models using solar wind parameters and/or IMF as drivers, usually, are used for now-casting (specification of ionospheric state) or forecasting 1-3 $\mathrm{h}$ ahead.

Empirical modeling is actually fitting of analytical functions to selected database, as the accuracy is assessed by standard deviation of the models from the data. Therefore, the accuracy of the models depends on two factors: selection of proper database and choosing analytical expression that accurately describe the real variations of ionospheric parameters. The proper adjustments of these two factors is the main challenge of the contemporary empirical models.

\section{Medium- and long-term ionospheric response to the changes in solar and geomagnetic activity}

This section includes results of the studies on ionospheric response to periodic changes of solar activity connected with solar rotation and also on long-term trends, connected with changes during solar cycle. Ionospheric response is latitude dependent and causes large horizontal gradients. These gradients are assessed by using GNSS measurements of the total electron content (TEC). Special attention is also paid on ionospheric behavior during the last prolonged solar activity minimum (2006-2009).

The main factor generating medium-term changes is the repeatable influence of active regions on the Sun's surface that rotate with a period of 27 days. In Section 2.1, Kutiev et al. (2012) demonstrate that the 27-day oscillations of the TEC at low-latitudes closely correlate with those of F10.7-index, considered as a proxy for the EUV solar irradiance. These authors analyzed the relative deviations of TEC (rTEC) over Japan obtained in the years 2000-2008 and found that the correlation between rTEC and F10.7 is highest during the maximum phase of solar activity, when the 27-day amplitude of rTEC is almost equal to its total deviation. They also show that the 27-day variation of rTEC plays a role of a background variation, which is disrupted by disturbances produced by geomagnetic storms.

Recurrent geomagnetic storms, produced by coronal holes, overcome the effect of solar irradiance on the ionosphere during declining and minimum phases of solar activity. In Section 2.2, Mukhtarov \& Pancheva (2012) reveal the main features of the global ionosphere response to the recurrent geomagnetic activity with period of 9 days. The latter correlates with recurrent solar wind HSSs which are related to coronal holes distributed roughly $120^{\circ}$ apart in solar longitude. The global observations of electron density profiles from the COSMIC satellites are used by the authors, for the period of time 1 October 200731 March 2009, when the 9-day oscillations in external forcing (solar wind, $K p$-index, and the NOAA Power Index) are strong.

Long-term trends in the upper atmosphere-ionosphere are reviewed in Section 2.3 by Lastovicka et al. (2012). The trends are due to simultaneous presence of several drivers, which behave in a different way, with the main driver being the increasing atmospheric concentration of greenhouse gases, mainly $\mathrm{CO}_{2}$ and long-term changes of geomagnetic and solar activity. Authors conclude that the role of space weather/climate in long-term changes and trends in the upper atmosphere-ionosphere was more important in the past, when it controlled the trends in ionospheric parameters, than it is at present, when the dominant controlling parameter seems to be increasing concentration of $\mathrm{CO}_{2}$.

Jakowski et al. (2011) reveal in Section 2.4 the coherent variations of TEC with F10.7 at three selected latitudes during the last solar cycle and assess the changes of the large-scale horizontal gradients with solar activity. They found that the sudden increase of EUV during the large CME (as that on 28 October 2003) has an immediate effect in TEC, preceding the geomagnetic storm.

Section 2.5 contains an original result on $f_{O} F 2$ variations during the prolonged period of extremely low solar activity between cycles 23 and 24. Comparison of $f o F 2$ variations in the last minimum with those in the previous solar minimum (1996) does not show marked difference, in compliance with F10.7 changes.

\subsection{Response of low-latitude ionosphere to 27 -day variations of solar and geomagnetic activity}

Kutiev et al. (2012) studied 27-day response of mid- and lowlatitude ionosphere represented by relative deviations of TEC over Japan during the period 2000 through 2008. Using wavelet analysis, they demonstrate that oscillations with periods around 27 days comprise the main periodicity of the ionosphere during this time. For statistical analysis, the hourly average TEC deviations (data manipulation is described by Kutiev et al. 2005) are fitted with two regression lines, representing a lower latitude band $\left(24^{\circ}-29^{\circ}\right) \mathrm{N}$ and an upper latitude band $\left(29^{\circ}-45^{\circ}\right) \mathrm{N}$ in the region of Japan. The mean rTEC of regressions are denoted as rTEC27 for southern and rTEC38 for northern sub-ranges. 


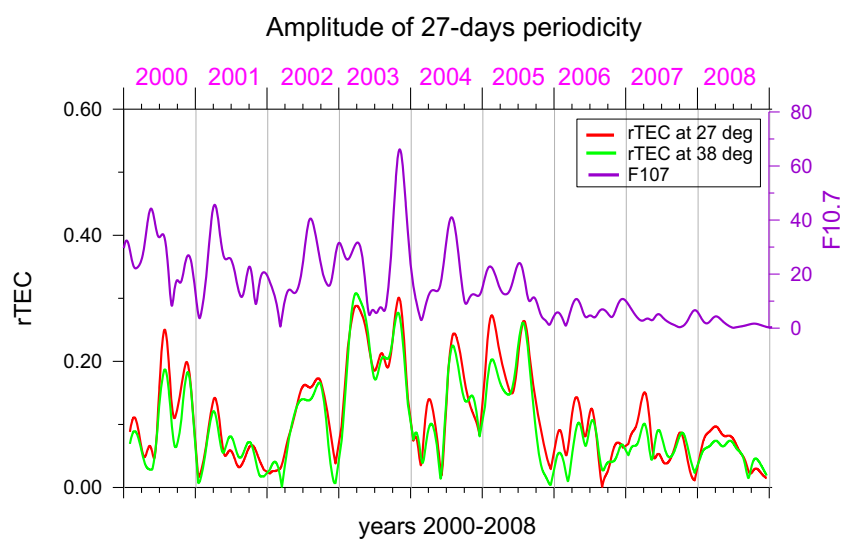

Fig. 1. The magnitude of 27-day oscillation in both rTEC27 (red line) and rTEC38 (green line) for the whole period of analysis 2000 2008. The magnitude of the 27-day oscillation in F10.7 is shown with the scale on the right (Kutiev et al. 2012).

In this analysis they examined the power spectra of ionospheric deviations, presented in the form of amplitude wavelet spectra. The rTEC oscillations with periods 5-30 days are transient phenomena that are most effectively identified by a wavelet transform method. The wavelet analysis presented here (Pancheva \& Mukhtarov 2000) employs the continuous Morlet wavelet, which consists of a cosine wave modulated by a Gaussian envelope.

Figure 1 shows the magnitude of 27-day oscillation in both rTEC27 (red line) and rTEC38 (green line) for the whole period of analysis 2000-2008. The magnitude of the 27-day oscillation in F10.7 is also shown with the scale on the right. The magnitude of 27-day periodicities in F10.7 is significantly higher in the period 2000-2005 than in the period 2006-2008. During this first period, covering the solar maximum and subsequent declining phase, the 27-day periodicities in rTEC are also the largest and quite well correlated in phase with F10.7 but not in magnitude. In the period 2006-2008 27-day periodicities in F10.7 are extremely small. The same periodicities in rTEC are smaller than those seen in the previous years. However, they remain significant but essentially uncorrelated in phase or amplitude with the same period changes in F10.7.

It is apparent that geomagnetic storms disrupt the underlying variation of rTEC and give rise to shorter term changes, which appear as intensification of shorter period oscillations. The ionosphere responds to geomagnetic forcing and recovers to the underlying longer period variation within 3-5 days, depending on the intensity of the storm. Figure 2 illustrates this behavior. A periodic variation, with period close to 27 days, is superimposed as the solid black curve on rTEC variations shown between day 180 and day 270, in 2004 in the top panel. This curve is not drawn to exactly represent the underlying large-scale variation but rather to provide a reference from which the small-scale deviations can be easily identified. Vertical arrows mark the start of some of these deviations, which coincide with the beginning of storms. From Figure 2 we find that the underlying variation in rTEC has close to a 27 -day period, that geomagnetic storms disrupt with both positive and negative variations in rTEC that return to the underlying baseline in 1-3 days. These assumptions were checked over the whole database. The temporal evolution of the disruption is caused by geomagnetic storms and the corresponding recovery depends on the frequency of storm on-sets. In many cases recoveries are interrupted by new storms, which make the statistical analysis difficult. During some periods in Figure 2, when the storms appear isolated from each other, the above behavior is readily seen. Two important features can be extracted from the visual inspection of data. The first is that the sign of disruption in the basic variation of rTEC depends on the phase of the variation. When rTEC is positive, disruption is toward negative values. When disruption appears during declining rTEC, the disruption is positive. The second feature is that the amplitude of the disruption is not proportional to the strength of the storm (measured by $K p$ or Dst).

\subsection{Thermosphere-ionosphere coupling in response to recurrent geomagnetic activity}

The aim of this subsection is to present the main features of the global ionosphere response to the recurrent geomagnetic activity with period of 9 days. The latter correlates with recurrent solar wind HSSs which are related to coronal holes distributed roughly $120^{\circ}$ apart in solar longitude. The global observations of electron density profiles from the COSMIC satellites are used for the period of time 1 October 2007-31 March 2009, when the 9-day oscillations in external forcing (solar wind, $K p$-index, and the NOAA Power Index) are strong. Here, only the response of the main F-region parameters $f_{o} F 2$ and $h m F 2$

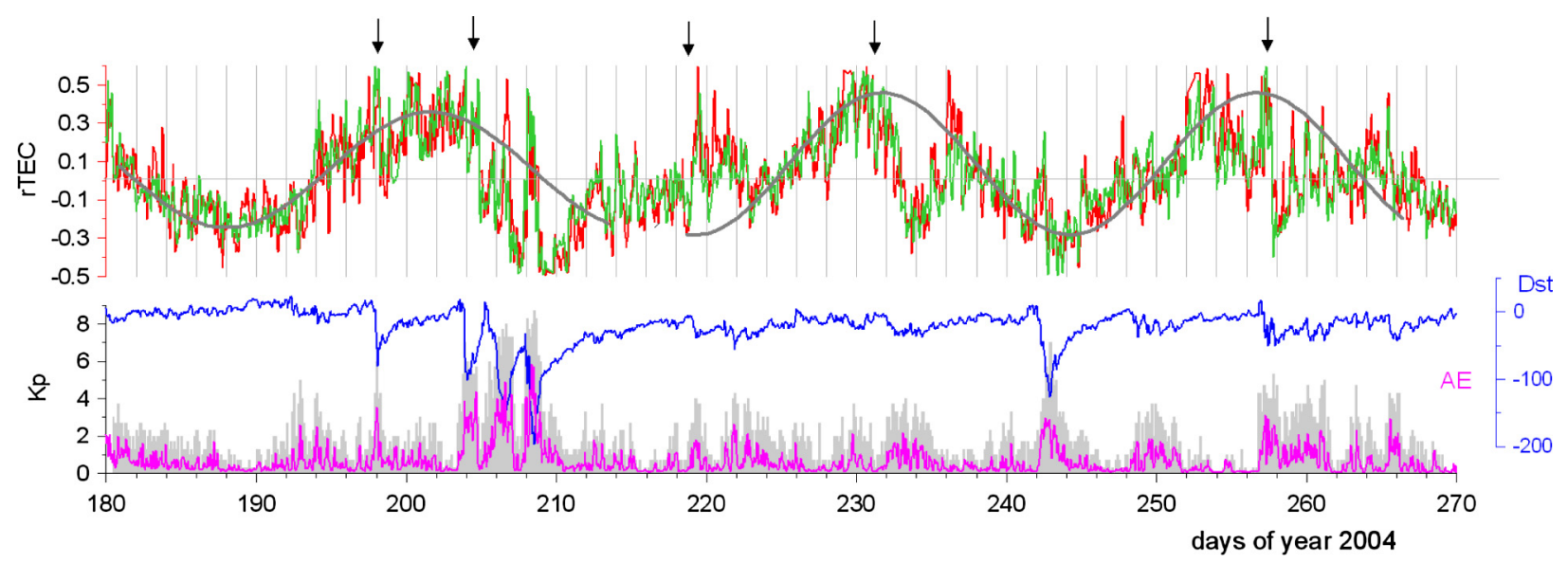

Fig. 2. Top: rTEC variations between days 180 and 270, in 2004, superimposed by a periodic variation (solid black curve), with period close to 27 days. Vertical arrows mark the start of some of these deviations, which coincide with the storms onsets (Kutiev et al. 2012). 

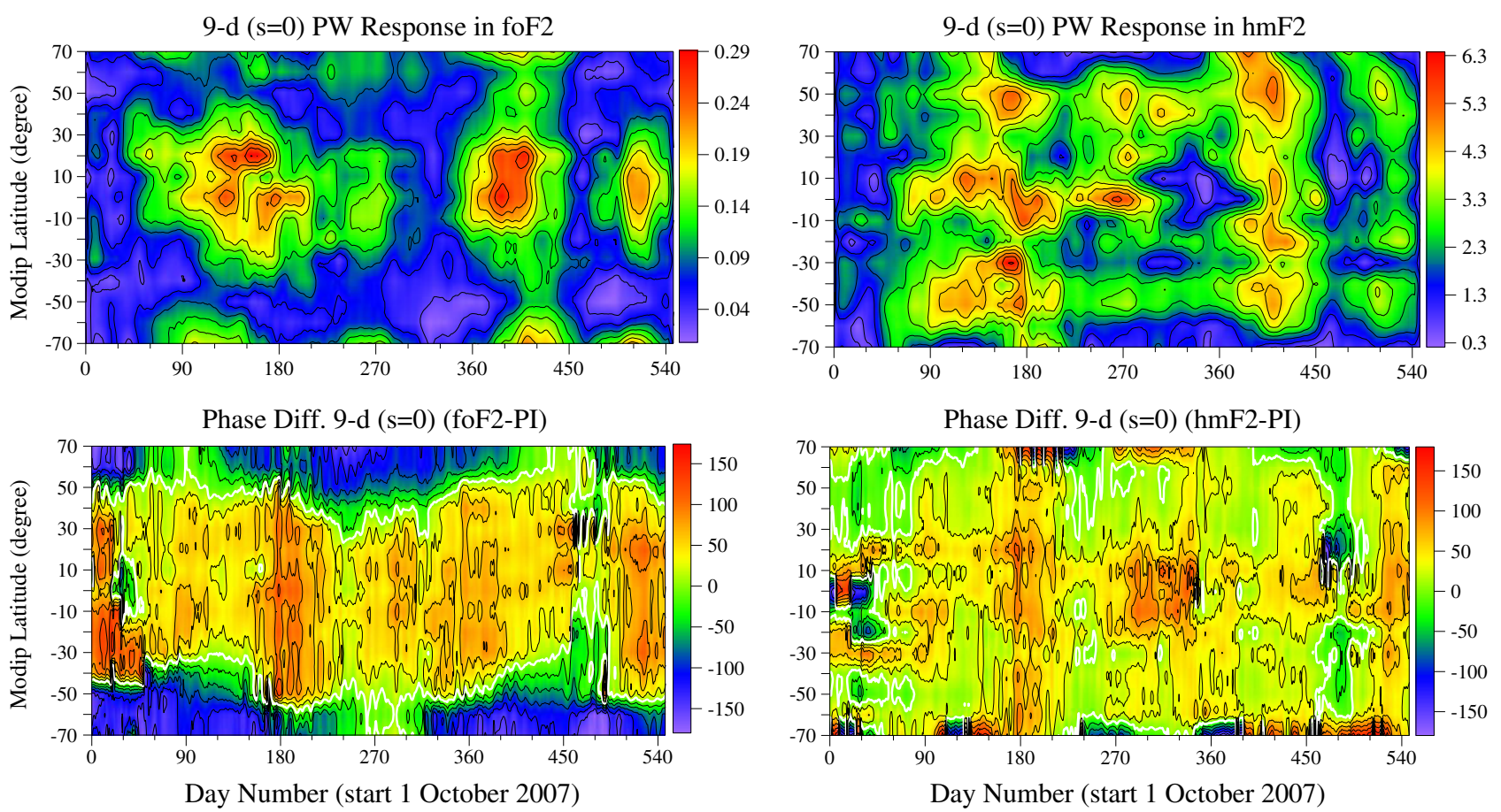

Fig. 3. (Upper row of plots) Extracted from the COSMIC data 9-day zonally symmetric $(s=0)$ waves seen in the ionospheric parameters: $f \circ F 2$ (left plot) and $h m F 2$ (right plot); (bottom row of plots) Phase difference between the ionospheric parameters foF 2 and the PI (left plot) and between $h m F 2$ and PI (right plot); the thick white line shows the zero phase difference (Mukhtarov \& Pancheva 2012).

will be shown. The results for the electron density at fixed height can be seen in Mukhtarov \& Pancheva (2012).

The upper row of plots in Figure 3 shows the latitude structures of the COSMIC 9-day wave amplitudes seen in $f_{0} F 2$ (left plot) and in $h m F 2$ (right plot). The 9-day ionospheric responses amplify concurrently with the external forcing. The low-latitude amplification of the $f o F 2$ 9-d response is well seen over the equator and at $\sim 20^{\circ} \mathrm{N}$ modip latitude. The $h m F 2$ shows clear amplifications over the equator and near $\pm 50^{\circ}$ modip latitudes; the latter $h m F 2$ amplifications coincide with minima of the $f o F 2$ 9-d responses. The Power Index (PI) is a measure of the external forcing of the thermosphere which leads to temperature changes and all consequences resulting from these changes (composition, chemical loss, and wind changes). Therefore, from physical point of view it is correct to examine the relationship between the ionospheric 9-d oscillations and those in the PI. The bottom row of plots in Figure 3 shows the difference between the phases (in degrees) of the 9-d oscillations in the $f_{o F} / h m F 2$ and in the PI (left/right plot). The thick white line shows the zero phase difference. When the phase difference is negative, it means the opposite ionospheric response to that of the external forcing, while the positive phase difference means that the ionospheric response lags behind that of the external forcing. The phase difference plot between $f_{o F}$ and PI (left plot) indicates the following regularities: (i) high-latitude $f o F 2$ 9-d oscillations are out of phase with those in PI; (ii) there is a clear seasonal dependence of the negative high-latitude $f o F 2$ 9-d wave response and this can be traced out by the zero phase difference line; it approaches high latitudes $\left( \pm 60^{\circ}\right)$ in winter and moves toward the equator (near $\pm 30^{\circ}$ ) in summer, and (iii) middle- and low-latitude $f_{o F}$ 9-d waves usually lag behind that in PI; the mean time delay is $\sim 1.5-2$ days $(\sim 60-$ $90^{\circ}$ ). The phase difference plot between $h m F 2$ and PI (bottom right plot) indicates that usually the ionospheric response lags behind that in the external forcing everywhere; while at $50^{\circ}$ modip the time lag is less than a day $\left(\sim 30^{\circ}\right)$ that above the equator is $\sim 1.5$ days $\left(\sim 60^{\circ}\right)$.

As the energy transfer is a combination of Joule heating and particle precipitations then the main drivers of the ionospheric response to recurrent geomagnetic activity are related to changes in the temperature, thermospheric neutral composition, and neutral winds. The heated gas is more buoyant than its surroundings, causing it to rise. Then the auroral heating alters the mean global circulation of the thermosphere. Whereas for quiet conditions there is a general upwelling in the summer hemisphere flow toward the winter hemisphere at higher levels, and downwelling in the winter hemisphere, the storm-time heating adds a polar upwelling and equatorward flow in both hemispheres. The increased equatorward wind at middle latitudes tends to push the ionosphere higher up along magnetic field lines, where the loss rate is lower. At high latitudes the upwelling brings air rich in the heavy molecular constituents $\mathrm{N}_{2}$ and $\mathrm{O}_{2}$ to high altitudes and the circulation carries this molecularrich air to midlatitudes, especially in the summer hemisphere, where the mean meridional circulation is already equatorward. At lower latitudes, the downwelling brings air with low concentration of molecular species. Since these species determine the loss rate of ions, the loss rate increases/decreases at higher/low latitudes.

Figure 3 shows that the 9-d wave responses in foF 2 are out of phase with those in PI at high latitudes and they lag behind that in the PI with a mean time delay of $\sim 1.5-2$ days at low latitudes. As the loss rate increases at higher latitudes and decreases at lower latitudes then the $f o F 2$ decreases at high latitudes and increases at low latitudes. The time lag of $\sim 1.5$ days is related to the needed time for the divergent equatorward flow to reach the lower latitudes. The bottom left plot demonstrates in a very clear way the seasonal dependence of the boundary between molecular enrichment and depletion areas. It is seen that the zero phase difference line approaches high latitudes 


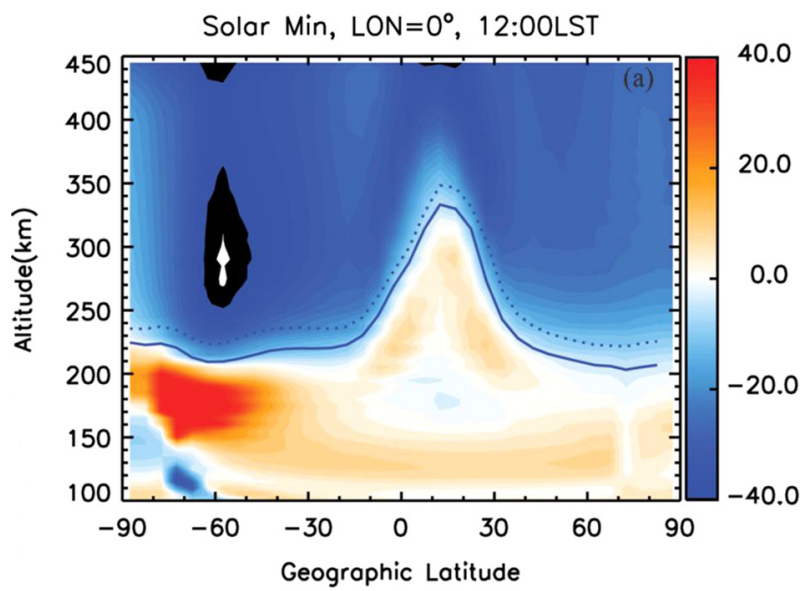

Fig. 4. Model simulation of trends in $f o F 2$ and $h m F 2$ at noon, longitude $0^{\circ}$, as a difference between the basic state and the state with doubled $\mathrm{CO}_{2}$ concentration. Dashed curve $-h m F 2$ for basic state; solid curve $-h m F 2$ for doubled $\mathrm{CO}_{2}$. After Qian et al. (2008).

in winter and moves to middle, even tropical latitudes during summer at both hemispheres. This is due to the fact that the summer-to-winter transequatorial thermosphere wind is against the storm-time generated equatorward flow in winter and in the same direction in summer.

The $h m F 2$ 9-d waves show maxima above the equator and near $\pm 50^{\circ}$ modip latitudes. This can be attributed to the 9-d modulated vertical drift in the equatorial region and to the periodical pushing of the ionosphere higher up along magnetic field lines. The latter apparently has maximum effect near $\pm 50^{\circ}$ modip latitudes where the storm-time equatorward flow still has strong meridional direction. The $h m F 2$ 9-d waves lag behind those in PI with a time delay of less than a day at $\pm 50^{\circ}$ modip latitudes and of $\sim 1.5$ days above the equator. Again these are the needed times for the divergent horizontal wind which blows equatorward to reach respectively middle and equatorial latitudes. It is worth noting that the $h m F 2$ 9-d wave amplifications at $\pm 50^{\circ}$ modip latitudes coincide with some minima of the 9-d waves in $f o F 2$. This means that when the ionosphere is pushed higher up along magnetic field lines by the storm-time equatorward flow its $h m F 2$ increases but the $f o F 2$ does not change due to the composition change effects on the $f o F 2$, i.e., since the ionosphere follows a constant pressure surface and this does not change the foF 2 .

In conclusion, it has to be noted that the ionospheric response to recurrent geomagnetic activity is really due to the same physical processes that disturb the ionosphere during classical ionospheric storms which are typically isolated events.

\subsection{Long-term trends in the upper atmosphere and ionosphere and space weather/climate}

Long-term trends and changes (longer than solar cycle) can partly be caused by long-term changes of trend drivers of solar/space weather origin like geomagnetic activity, which in terms of the aa-index was increasing over almost the whole 20th century (e.g., Mursula \& Martini 2006), even though now it is low. On the other hand, long-term changes of background conditions in the upper atmosphere-ionosphere system, which are of solar origin, may modify effects of other drivers of long-term trends, and long-term trends themselves modify background conditions for effects of space weather phenomena on the upper atmosphere-ionosphere system. Therefore it is necessary to investigate the impact of space weather/climate on long-term trends in the upper atmosphere-ionosphere system.

Long-term trends in the upper atmosphere-ionosphere are a complex problem due to simultaneous presence of several drivers of trends, which behave in a different way: increasing atmospheric concentration of greenhouse gases, mainly $\mathrm{CO}_{2}$, longterm changes of geomagnetic and solar activity, secular change of the Earth's main magnetic field, remarkable long-term changes of stratospheric ozone concentration, and very probably long-term changes of atmospheric dynamics, particularly of atmospheric wave activity (Lastovicka 2009; Qian et al. 2011; Lastovicka et al. 2012). Whereas $\mathrm{CO}_{2}$ concentration is quasi-steadily increasing, other drivers change their trends with time even to opposite (solar and geomagnetic activity, stratospheric ozone), or change trends with location (Earth's main magnetic field), or with latitude (geomagnetic activity), or are largely unknown but probably unstable in space and time (atmospheric winds and waves). Consequently, the trends in the upper atmosphere-ionosphere system cannot be stable; they have to change in time and space (e.g., Lastovicka et al. 2012). Such trends might be represented by piecewise linear trends.

As for solar activity, it has decreased in the second half of the 20th century after the 1957-1958 maximum, and it is low in recent years. This is a tendency opposite to what is required to explain the observed ionospheric trends in the E and F1 regions (Lastovicka 2009). Moreover, the effect of solar activity, on the solar cycle time scales, is usually reduced when long-term trends are computed both in the ionosphere and thermosphere as the solar cycle effect is much larger than trend. Different corrections to solar activity are one of sources of differences between different trend results in the F2-region parameters, $f o F 2$ and $h m F 2$. Thus, solar activity itself has little or no direct effect on observed ionospheric trends. However, it is necessary to mention that trends may be quantitatively different under solar activity maximum and minimum conditions, which is the case for thermospheric density (e.g., Emmert et al. 2008). The reason is much larger relative role of the $\mathrm{CO}_{2}$ radiative cooling compared to the NO radiative cooling under solar minimum conditions as confirmed by SABER/TIMED measurements (Mlynczak et al. 2010). This is an indirect effect of solar activity on trends in the thermosphere and ionosphere.

Another potentially important driver of trends is geomagnetic activity, which was increasing throughout almost the whole 20th century (Mursula \& Martini 2006) but now it is low. Bremer et al. (2009) summarized various results on geomagnetic activity control of trends in the ionosphere and found that the change of dependence of trends on long-term change of geomagnetic activity, i.e., the loss of dominant geomagnetic activity control of ionospheric trends, occurred around 1970 in the E region, in the early 1990 s in the F1 region, and around 2000 in the F2 region as illustrated in Figure 5 for two European stations Roma and Slough/Chilton. Trends in the height of maximum of $\mathrm{F} 2$ region, $h m F 2$, lost geomagnetic activity control much earlier than trends in $f o F 2$ (Lastovicka et al. 2012). Thus at present the long-term changes in geomagnetic activity are not the main driver of trends in any variable, contrary to the past, when it probably controlled ionospheric trends (Lastovicka et al. 2012). This is, however, valid only for low and middle latitudes. In the auroral zone, which is generally under continuous and much stronger geomagnetic/magnetospheric activity control than low and middle latitudes, the trends seem to be still under dominant geomagnetic control as suggested by the $f_{o} E$ trends as observed at auroral station Tromso 

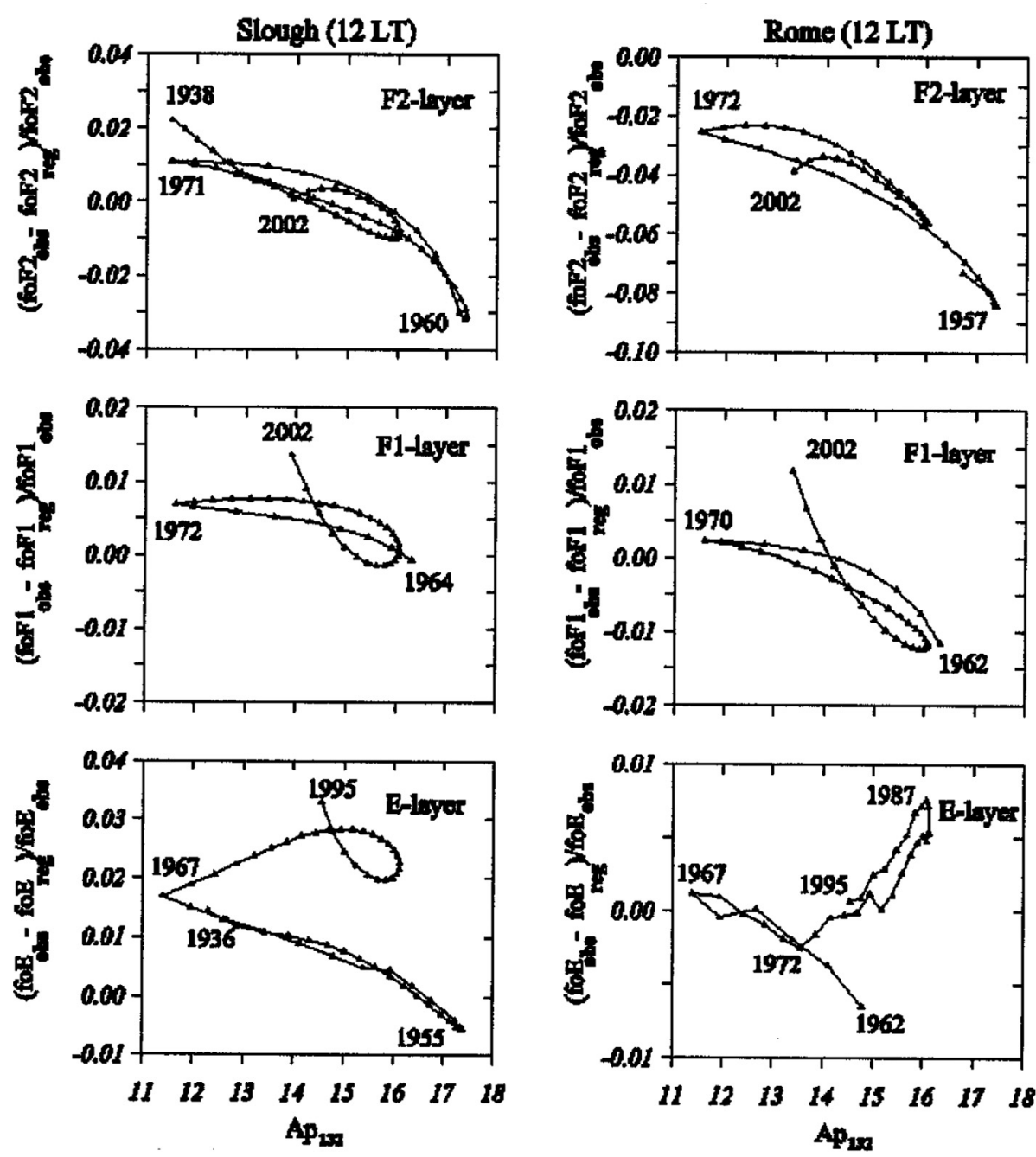

Fig. 5. Relationships between $\delta f o F 2$ (top panels), $\delta f o F 1$ (middle panels) and $\delta f o E$ (bottom panels), and $\mathrm{Ap}_{132}$ variations for Slough (left panels) and Rome (right panels). The change in the type of the dependences appeared earlier in the E region, later in the F1 region, and eventually it began to appear in F2 region. After Bremer et al. (2009).

(Hall et al. 2011). Recent trends in the mid- and low latitude $f o E$ and $f o F 1$ are a slight increase, and in $f o F 2$ in day-time a very small decrease, probably due to changes in minor constituent chemistry and various temperature-dependent reactions and loss rates. This is consistent with model calculations of changes due to increasing concentration of $\mathrm{CO}_{2}$ shown in Figure 4. An increase of electron density at heights of $f_{o E}(\sim 110 \mathrm{~km})$ and foF1 $(\sim 200 \mathrm{~km})$ in middle and lower latitudes is well visible. A decrease of $h m F 2$ (seen as the difference between the basic state and the state with doubled $\mathrm{CO}_{2}$ concentration) is also evident, whereas $h m F 2$ is close to the level of no change in $f o F 2$, it is located in the region of a slight decrease of electron density and, thus, of $f_{o} F 2$. This pattern is qualitatively consistent with the observed trends in ionospheric parameters and a weak $\mathrm{CO}_{2}$ related trend in $f_{o} F 2$ explains also the delayed loss of dominant influence of long-term change of geomagnetic activity on $f o F 2$ trends.

Thus the role of space weather/climate in long-term changes and trends in the upper atmosphere-ionosphere was more important in the past, when it controlled the trends in ionospheric parameters, than it is at present, when the dominant controlling parameter seems to be increasing concentration of $\mathrm{CO}_{2}$.

\subsection{Latitude-dependent response of TEC to solar EUV changes}

Since the solar EUV radiation varies by a factor of about 2 within a solar cycle (Lean et al. 2003), it is expected that the ionospheric TEC is highly correlated with solar activity changes. We checked this assumption by comparing TEC obtained at three selected sites in Europe (cf. http://swaciweb. dlr.de) with the solar activity dynamics represented by the radio flux index F10.7 which is also a proxy for EUV radiation changes (see Fig. 6).

Although TEC is subjected to a clear seasonal modulation, the general behavior of TEC is highly correlated with F10.7 (e.g., Jakowski et al. 1991, 2011). Whereas the dynamic ratio between TEC maximum and minimum is about 8 at day-time over Europe, the same ratio is about 5-6 for night-time conditions during solar cycle 23 (see Fig. 7). Furthermore, it can be seen that due to the lower incidence angle of the solar radiation at lower latitudes, TEC at $35^{\circ} \mathrm{N}$ is principally higher than TEC at $65^{\circ} \mathrm{N}$. Differences between both latitudes are always positive at day-time and reach up to 20 TECU while following the solar cycle dynamics. During night-time, the situation is indifferent for the difference $\operatorname{TEC}\left(50^{\circ} \mathrm{N}\right)-\operatorname{TEC}\left(65^{\circ} \mathrm{N}\right)$, i.e., positive and negative differences occur. The difference 

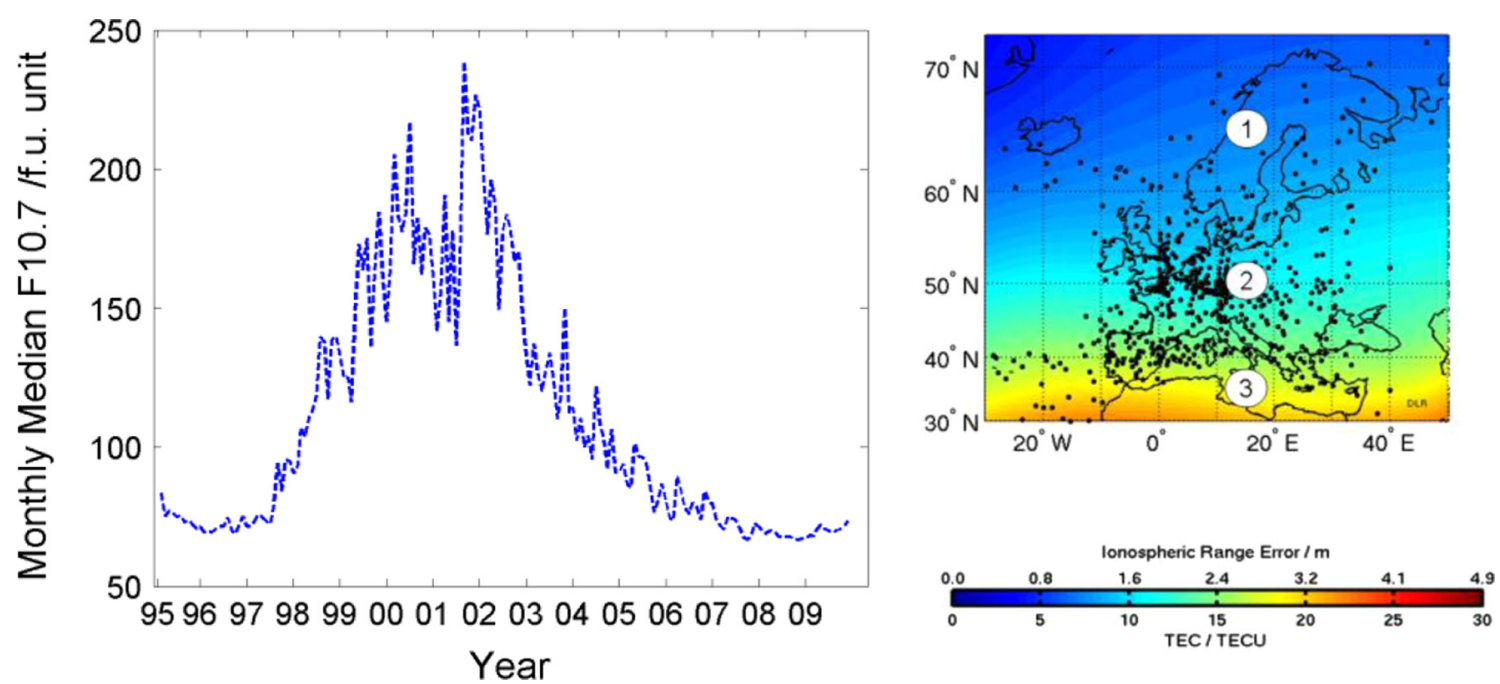

Fig. 6. Left panel: solar activity variation (F10.7) from 1995 to 2009 covering solar cycle 23 (1996-2008). Right panel: location of three test sites at which TEC is extracted from regularly produced GNSS-based TEC maps over Europe (Jakowski 1996; Jakowski et al. 2011).
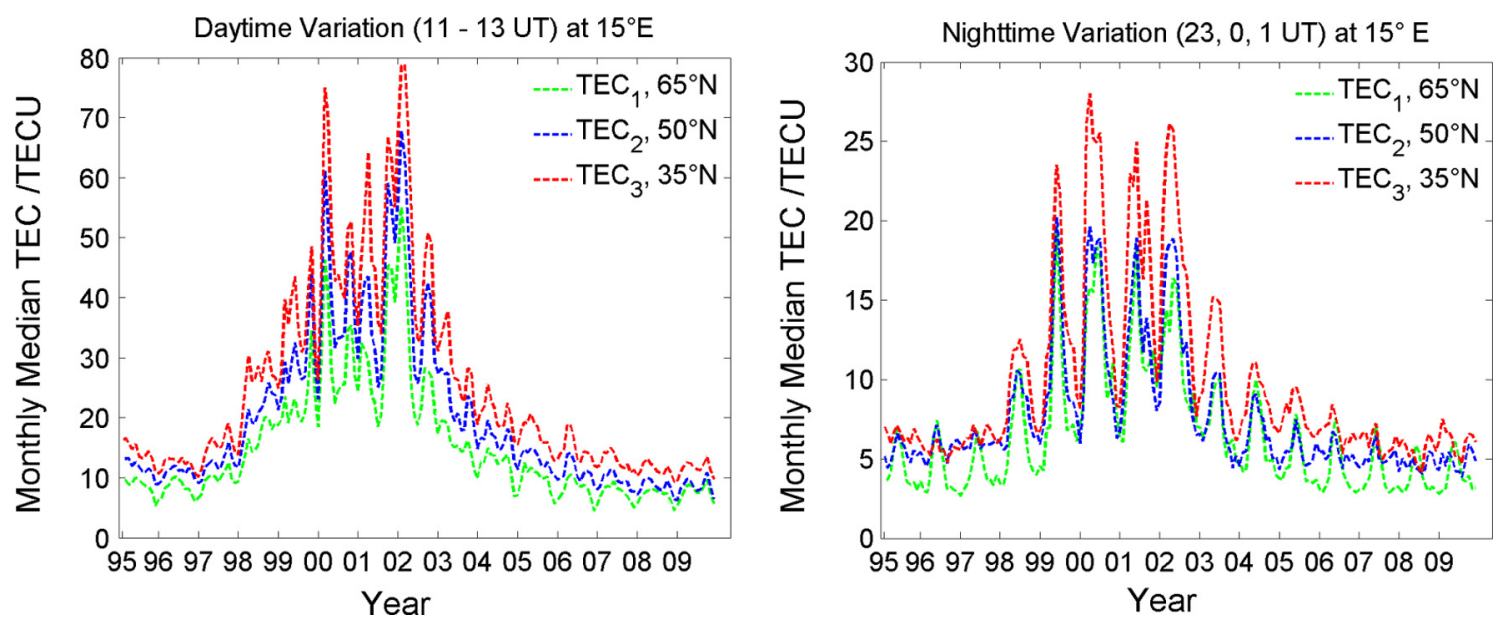

Fig. 7. Day-time variation of TEC averaged over 12-14 LT at three selected points in Europe (left panel). Night-time variation of TEC averaged over 00-02 LT at three selected points in Europe (right panel). Selected TEC unit: 1 TECU $=1 \times 10^{16} \mathrm{~m}^{-2}$.

$\operatorname{TEC}\left(35^{\circ} \mathrm{N}\right)-\operatorname{TEC}\left(50^{\circ} \mathrm{N}\right)$ is almost positive and follows the dynamics of the solar cycle as day-time differences. Such TEC gradients are important for GNSS applications. Here averaged meridional TEC gradients between $35^{\circ} \mathrm{N}$ and $50^{\circ} \mathrm{N}$ may reach about $2.5 \mathrm{~mm} / \mathrm{km}$ at L1 GPS frequency, which is far away from threat model values of the order of $100 \mathrm{~mm} / \mathrm{km}$ (e.g., Mayer et al. 2009). When considering latitudes below $30^{\circ} \mathrm{N}$, a dramatic increase of meridional gradient values is expected in the crest region which needs further investigation. Gradients may considerably enhance during ionospheric storms (Jakowski et al. 2008; Mayer et al. 2009). Sudden increases of EUV radiation during solar flares are immediately visible in TEC data as it has clearly been shown during the strong solar flare on 28 October 2003 (Jakowski et al. 2008).

\subsection{Ionospheric behavior during prolonged minimum of the 23/24 solar cycle}

The solar minimum between solar cycles 23 and 24 was significantly longer than it has been expected. Lastovicka et al. (2006) pointed out that besides other aspects, the significance of understanding of the solar minimum lies in revealing the nat- ure of solar variability, its effects on geospace, and assessing the predictability of current models. Within the minimum of cycle 23/24 measurements from instruments placed on SOHO (the Solar and Heliospheric Observatory) and TIMED (the Thermosphere-Ionosphere-Mesosphere Energetics and Dynamics) satellites indicated that solar EUV irradiance levels were lower comparing with previous solar minimum, which led to lower thermospheric density and temperature. Although solar EUV is primary controller of the temperature and density of the thermosphere and ionosphere, contributions from geomagnetic activity are also significant (Solomon et al. 2010). The prolonged solar minimum in 2006-2009 gave us a unique possibility to explore ionospheric behavior under extremely low solar activity conditions, particularly ionospheric reaction to occasional very moderate geomagnetic disturbances. Our analysis was aimed at variability of the ionospheric F2-layer critical frequency $f o F 2$ and peak height $h m F 2$ above middle latitudes under low solar activity conditions.

In total, the created database comprises values of $f_{o} F 2$ and $h m F 2$ for nine middle latitude stations which operate the DPS (Digisonde Portable Sounder). We compared monthly medians of the F2-layer main parameters for the solar minimum of the 


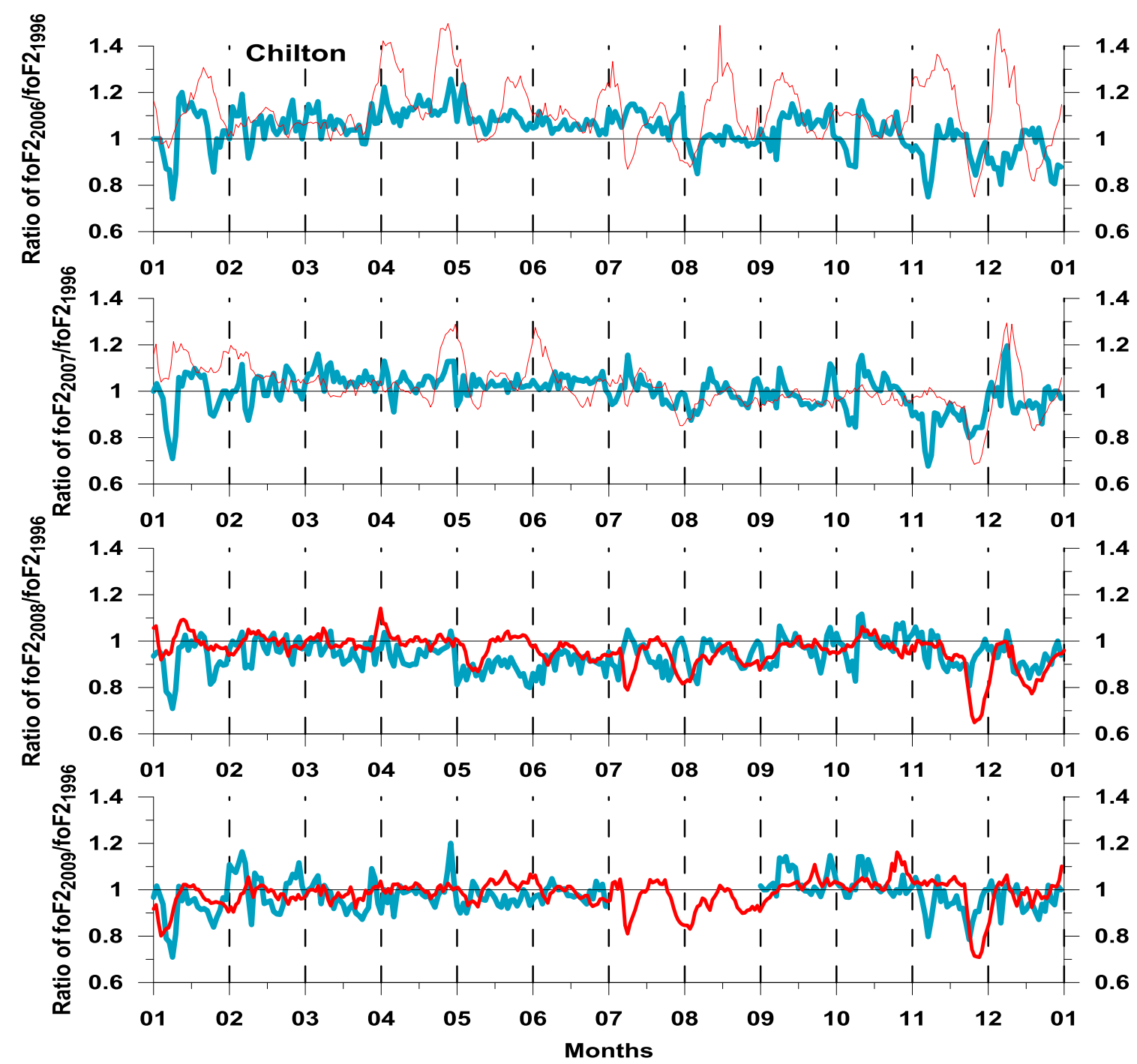

Fig. 8. Ratio of the hourly medians of $f o F 2$ observed during 1996 and those measured at 2006-2009 for Chilton.

cycles $22 / 23$ and $23 / 24$. To evaluate the effects of geomagnetic disturbances on the ionospheric F2-layer, we used hourly measurements of $f o F 2$ and $h m F 2$ and their 27-days running means centered on the culmination (minimum Dst) day of each analyzed geomagnetic disturbance. Both $f_{o F}$ and $h m F 2$ values were automatically obtained from the ARTIST software (Reinisch \& Huang 1983). The disturbed periods were analyzed using constituently checked data.

The blue curves in Figure 8 represent the ratio of the $f_{o F}$ monthly medians observed during 2006-2009 above Chilton to those measured in 1996. The red curve is for the ratio of the daily $10.7 \mathrm{~cm}$ solar radio flux (F10.7) observed for the period 2006-2009 to the 1996 values. The course of the ratio indicates that, in general, comparing to 1996 , the $f o F 2$ decreased mostly during the winter 2006-2009 and summer 2008. We obtained similar results also for Pruhonice, except January of each analyzed year, where the ratio was mostly positive. For the selected middle latitude stations the ratio of the peak critical frequency fit to the range of $(-0.7)-1.5$. Solomon et al. (2010) mentioned that NCAR Thermosphere-Ionosphere Electrodynamics General Circulation Model (TIE-GCM) model simulations for $\sim 97-600 \mathrm{~km}$ altitude showed, that the estimated change in total EUV energy input is approximately commensurate with the measured density change. Our analysis partially supports the model results, nevertheless, the observations also gave notice about importance of other factors (e.g., geomagnetic activity, location, season, daytime, tropospheric effects). Recently, widely discussed influence of the greenhouse gases on the Earth's upper atmosphere seems to be responsible only for a small portion of the observed density change (Solomon et al. 2010).

Figure 9 shows the level of geomagnetic activity for 1996 (top panel) and 2006-2009 (panels below) represented by monthly means of the daily $K p_{\text {sum. }}$. It is evident that the lowest geomagnetic activity has been observed in 2009, and a wellpronounced semiannual variation of geomagnetic activity of the solar cycle 22/23 minimum was not present during the minimum of $23 / 24$.

There are several physical processes that can affect the ionospheric F-region electron density profile. The lower thermospheric temperatures, as a consequence of an unusually long minimum in solar extreme-ultraviolet flux, not only decreased density, but the contraction of the upper atmosphere also lowered the height of the peak of the ionospheric F-layer. In general, the differences between monthly medians of foF2 obtained for solar minimum years 1996 and 2006-2009 and 


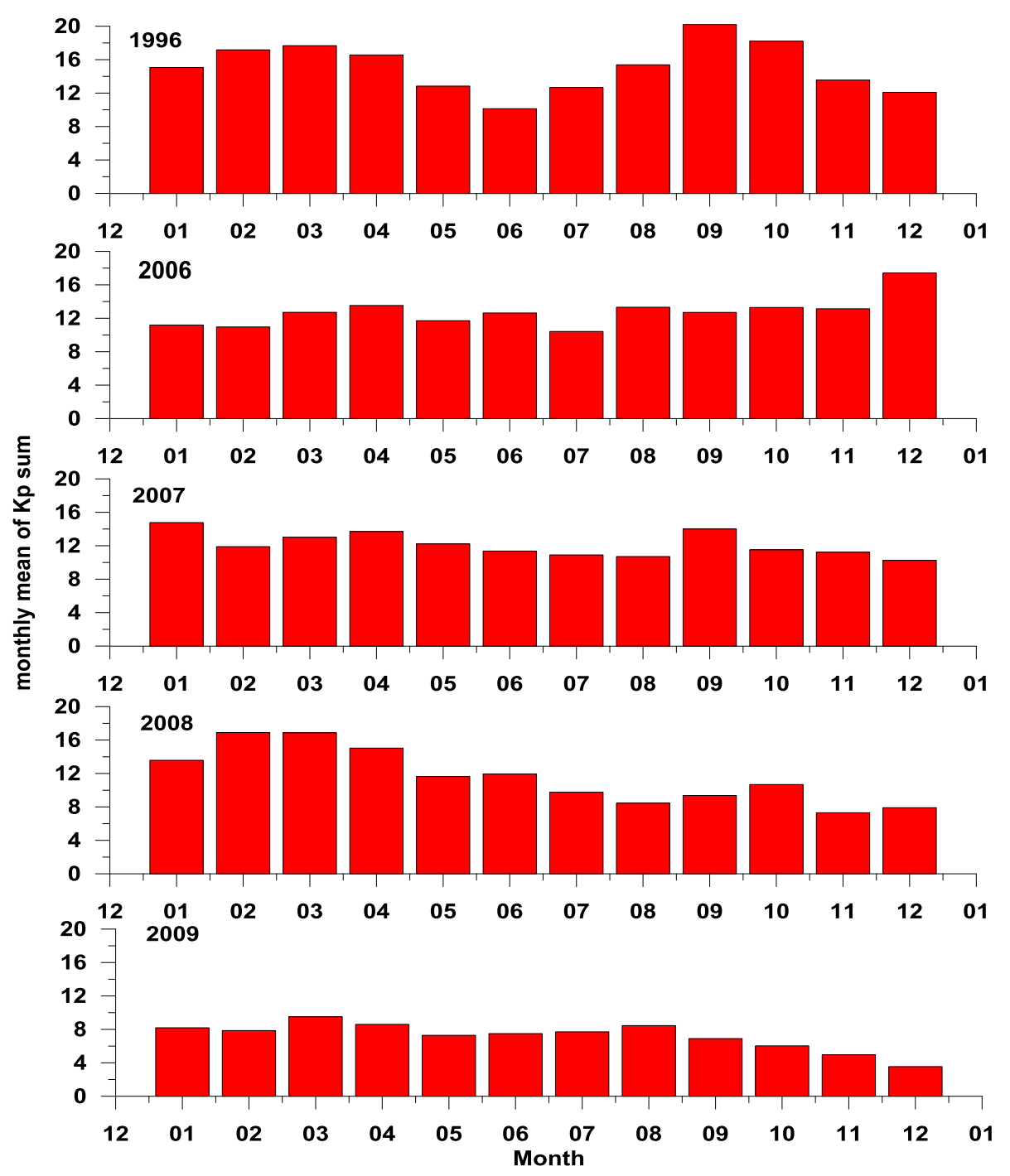

Fig. 9. Monthly means of the daily $K p_{\text {sum }}$ for 1996 (top panel) and 2006-2009 (panels below).

for selected middle latitude stations fit to the range of $(-0.7)$ $1.5 \mathrm{MHz}$.

\section{Storm-time ionospheric response to the solar and geomagnetic forcing}

The behavior of ionospheric midlatitudes during the prolonged period of very low solar activity, with F10.7 not exceeding 80, is subject of the original study, whose results are presented in Section 3.1. The analysis includes 15 minor and moderate CIR-driven storms in the period 2006-2009. The main conclusion is that the deviations of $f o F 2$ and $h m F 2$ from their quiet levels during the analyzed period are higher than expected and comparable with those induced by strong CME-driven storms.

In Section 3.2, L. Perrone and M. Parisi present an original study on the sudden increase of the polar cap absorption (PCA) linked to a Halo CME on 9 May 2005. The CME has given origin to SPE which reaches the peak simultaneously with the beginning of SSC of a geomagnetic superstorm that occurred on 14 May 2005. The behavior of SPE and consequently the PCA characteristics allow assuming that the latter event is connected with two magnetic clouds (MC) near Earth, not usual for a single $\mathrm{MC}$ originated from that $\mathrm{CME}$.

During the strong CME-driven storms, the ring current intensity sharply increases and the plasma sheet particles with higher energies penetrate deeper into atmosphere of the auroral zone and produce additional ionization. Using radio occultation measurement to reconstruct the electron density profiles in the E region, Mayer \& Jakowski (2009) have collected cases when the maximum density of the E region exceeds that of the F2layer. The geographical distribution of these events, shown in Section 3.3, fits very well with the boundaries of the auroral zone.

\subsection{Ionospheric response to geomagnetic activity during prolonged solar minimum}

The prolonged solar minimum in 2006-2009 offers a unique possibility to explore ionospheric behavior under extremely low solar activity conditions, particularly ionospheric reaction to occasional very moderate geomagnetic disturbances. The present analysis was aimed at variability of the ionospheric F2-layer critical frequency foF 2 and peak height $h m F 2$ above middle latitudes under low solar activity conditions. The minor and moderate geomagnetic storms, which predominantly occur 

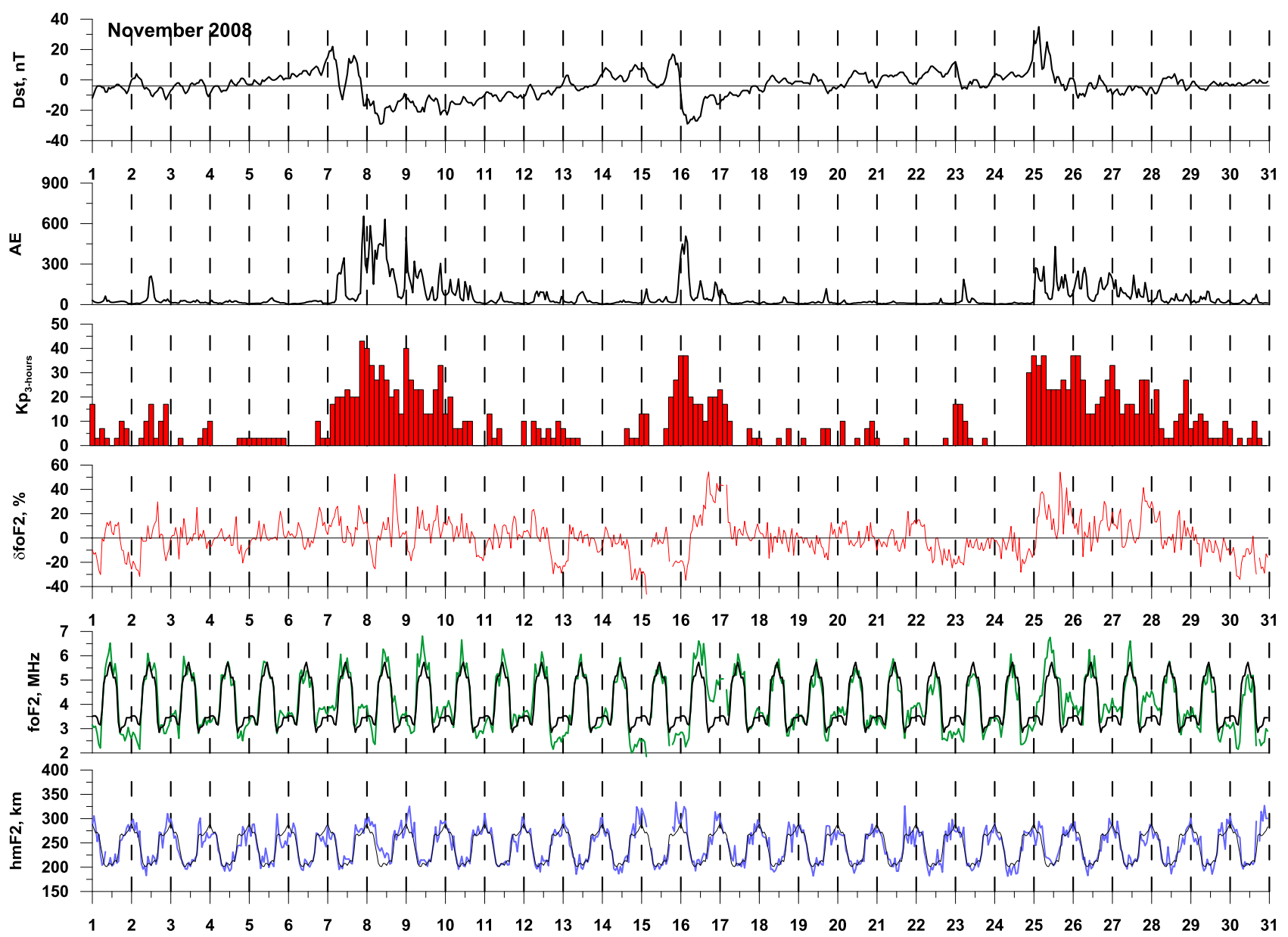

Fig. 10. Ionospheric F2-layer behavior as it was observed in November 2008 above Pruhonice observatory. The top panels show the course of Dst, AE, and $K p$ indices. Two bottom panels are for $f o F 2$ (solid green line) and $h m F 2$ (solid blue line). The solid black line represents $27-$ days running mean. The middle panel gives difference between the daily foF2 and its 27 -days running mean in percentage.

during this period, are assumed to represent the CIR-driven storms. Fifteen recurrent storms were selected to analyze variation of $f_{o F}$ and $h m F 2$. Results for November 2008 for Pruhonice are presented in Figure 10. Three top panels are for $D_{\text {st }} A E$ and $K p$ indices, respectively. Two bottom panels show variation of the hourly values (green and blue plots) and the 27-days running means (black curves) of $f o F 2$ and $h m F 2$. The plot in the middle represents differences between daily observations and their mean values. During November 2008 three minor-to-moderate disturbances occurred. We observed changes in $f o F 2$ up to $60 \%$ during these events, which at middle latitudes are typical rather for strong geomagnetic storms than for minor and moderate disturbances. We observed both positive and negative effects on electron density (positive effects were larger).

Table 1 summarizes results of the deviations, obtained between the measured values and their medians for all 15 analyzed events and for four midlatitude stations. The analysis of the effects of these magnetic disturbances, occurring within the period 2006-2009 on ionospheric F2-layer, showed significant departure of the main peak parameters from the corresponding 27-days running means. In the majority of the cases the differences were comparable with the effects of CME-driven strong magnetic storms. Deviations in Table 1 show that the ionospheric response to geomagnetic storms during the extreme solar minimum remains high, not proportional to the intensity of the storms.
Table 1. Range of the differences between the disturbed-time $f o F 2$ and $h m F 2$ values and corresponding 27-days running means (\%), obtained for 15 analyzed minor-to-moderate magnetic disturbances within the prolonged solar minimum (2006-2009). The analyzed period of each disturbance includes the culmination day and at least two days of the recovery phase.

\begin{tabular}{crcrc}
\hline \hline $\begin{array}{c}\text { Ionospheric } \\
\text { stations }\end{array}$ & Pruhonice & Chilton & Rome & Grahamstown \\
\hline$\Delta f o F 2(\%)$ & $24-102$ & $25-86$ & $28-116$ & $23-80$ \\
$\Delta h m F 2(\%)$ & $17-43$ & $15-74$ & $20-90$ & $24-41$ \\
\hline
\end{tabular}

\subsection{Polar cap absorption event of May 2005 in Antarctica}

An essential space weather objective is the understanding and the prediction of the consequences at the Earth of Coronal Mass Ejections after its evolution through the interplanetary medium.

One of the most intense events on the Sun during the declining phase of solar cycle 23, occurred on May 2005 is analyzed in this paper. This is an event thought to be due to a single solar source (Zhang et al. 2007) and with quiet geomagnetic conditions that prevailed before and after the storm. Hence, its geomagnetic and ionospheric effects could be gauged very accurately. The characteristics of May 2005 event and the properties of the correlated observations of ionospheric absorption, obtained by a 


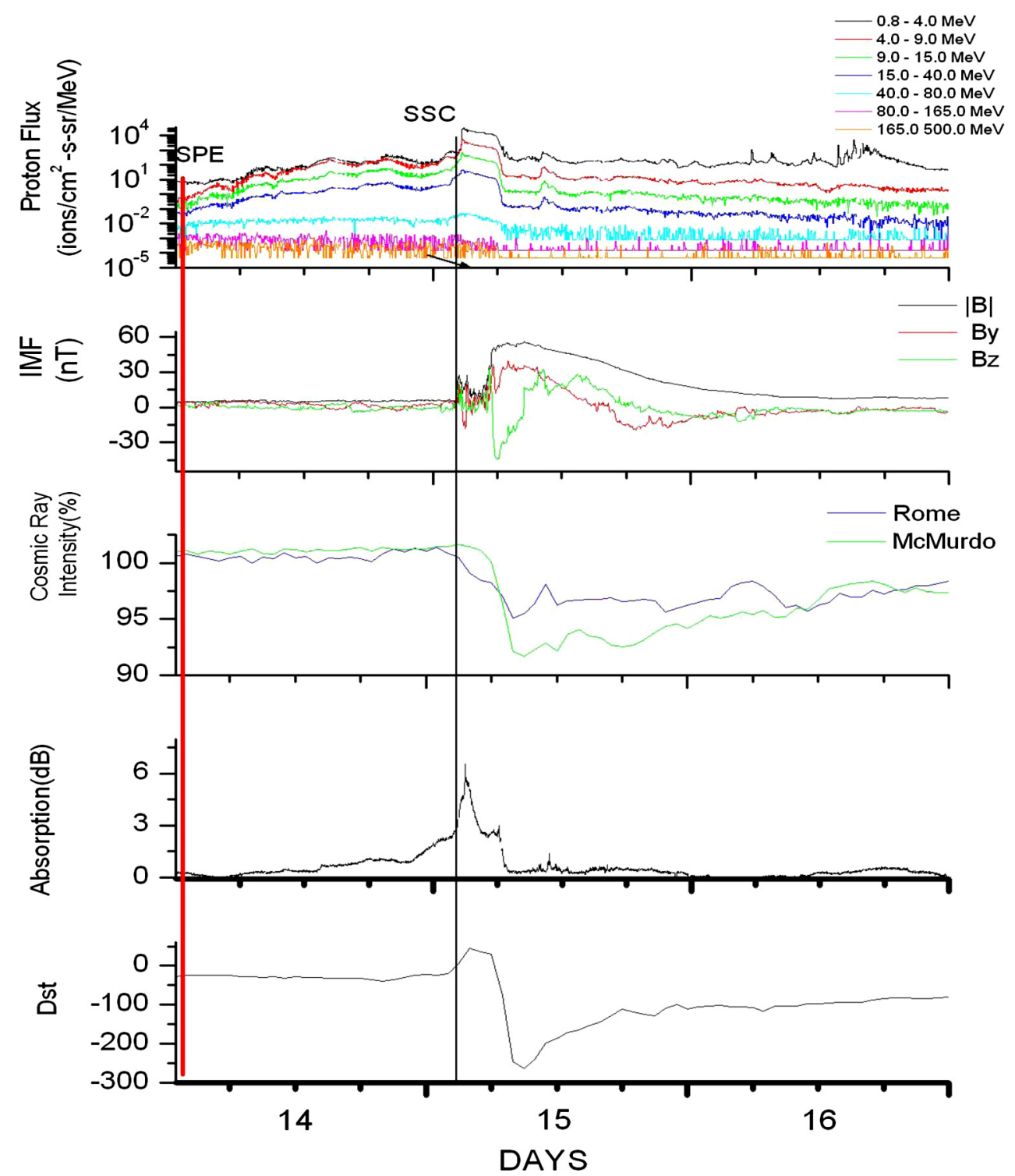

Fig. 11. From top to bottom: differential solar proton flux, Interplanetary Magnetic Field (data in GSM coordinates obtained from ACE spacecraft), cosmic ray data, ionospheric absorption, and Dst index during 13-16 May 2005.

$30 \mathrm{MHz}$ riometer installed at Mario Zucchelli Station (MZS-Antarctica, Perrone et al. 2004), and of geomagnetic activity at the ground level are investigated. Solar events are studied by using the characteristics of CME measured with SoHO/LASCO coronagraphs and the temporal evolution of solar energetic particles in different energy ranges measured by GOES 11 spacecraft (Bremer et al. 2009; Perrone et al. 2009).

The solar region AR0759 appeared on the east limb on May 9 produced on 13 May two solar flares, C1.5 at 12:49UT and M8 at 16:32UT, going to the central meridian. The last solar flare linked to an Halo CME with a speed of $1689 \mathrm{~km} / \mathrm{s}$. The transit time of Interplanetary CME (ICME), that contains two attached but non-merged Magnetic Clouds (MCs) (Dasso et al. 2009), with respect to the origin of CME is of $33.5 \mathrm{~h}$ at 1 AU. Because a single solar source cannot originate two MCs, the MCs are linked to the two solar flares of 13 May (Dasso et al. 2009).

The CME has given origin to SPE that reaches the peak simultaneously with the beginning of SSC (Fig. 11). This SPE determined an ionospheric absorption of $6.5 \mathrm{~dB}$. The peak of SPE $(>10 \mathrm{MeV})$ is 3140 (pfu) and occurs, approximately, with the interplanetary shock occurrence, this is a typical behavior of central meridian events. The peak of ionospheric absorption occurs after 19 min from SPE peak $\left(E_{0}<40 \mathrm{MeV}\right)$. In fact, the ionization in the $\mathrm{D}$ region during PCA events is due mainly to protons with energy in the range $1-100 \mathrm{MeV}$ that can reach an altitude between 30 and $80 \mathrm{~km}$. The ionospheric absorption could be higher but the peak of SPE occurred during nighttime condition $\left(\chi>96^{\circ}\right)$. The large difference between day and night absorption intensities for equal precipitating fluxes of solar particles is a characteristic feature of PCA events. This feature is mainly a consequence of switching off the photo-detachment of negative ions, thus the negative ions created by attachment remain below $80 \mathrm{~km}$ at night and this results in electron density depletion.

The IMF Bz component turned southward, remained south between 05:32 UT and 08:20UT on May 15 reaching a value of $-44 \mathrm{nT}$ at $05: 56 \mathrm{UT}$ and the high solar wind velocity (close to $1000 \mathrm{~km} / \mathrm{s}$ ) are the cause of a geomagnetic superstorm occurred with a $D_{\text {st }}$ peak excursion of $-263 \mathrm{nT}$.

The arrival of a single $\mathrm{MC}$, in general, is connected to a decreasing of SPE and consequently of the ionospheric 


\section{Kutiev et al.: Solar activity impact on upper atmosphere}
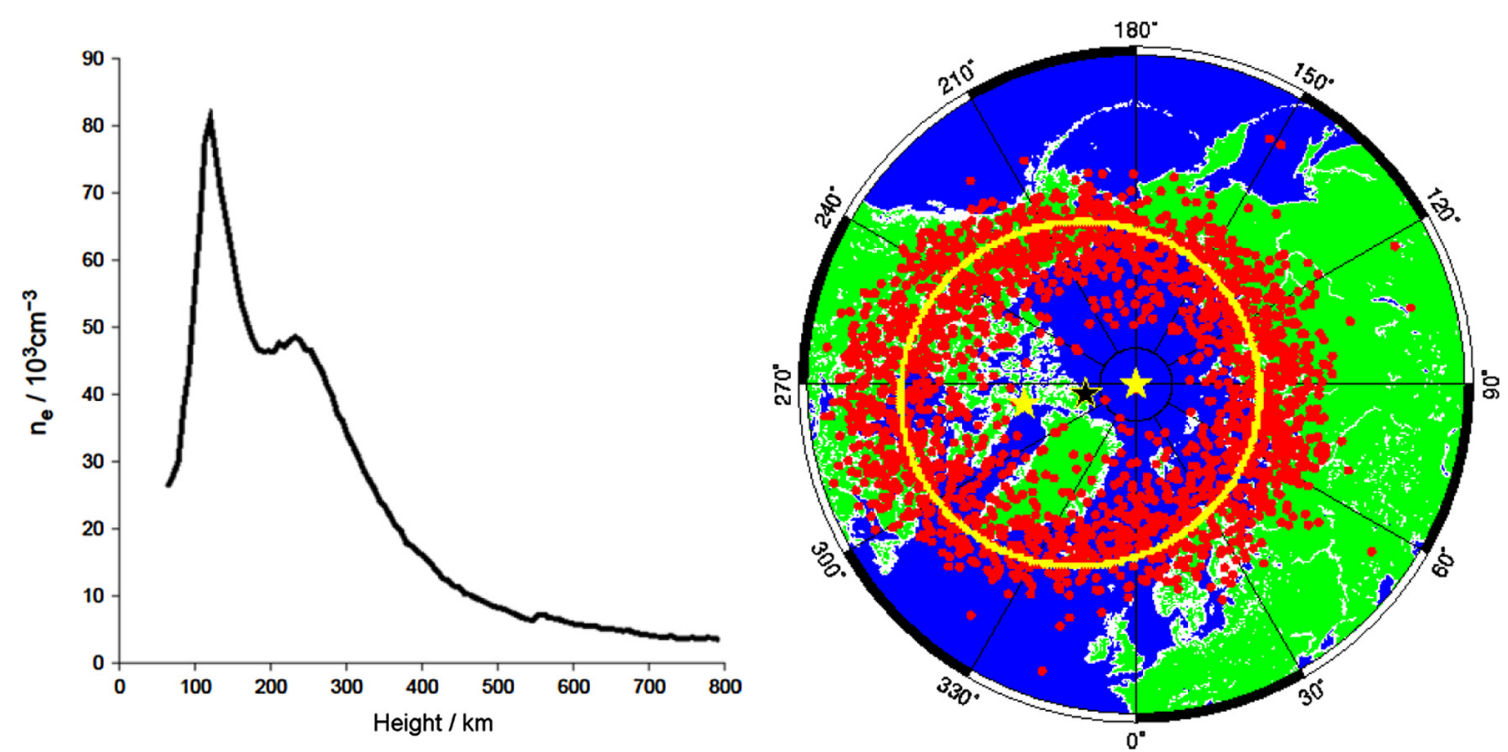

Fig. 12. Left panel: typical electron density profile as they can be derived from GPS RO measurements onboard Formosat3/COSMIC, CHAMP, and GRACE satellites. Right panel: ellipse fit to the distribution of ELDI profiles, which show enhanced E-layer ionization (red dots). The yellow stars mark the focal points of the ellipse; the black star marks the center point of the circle fit which coincides with the position of the geomagnetic pole (Mayer \& Jakowski 2009).

absorption as it is observed in this case when Bz flows Southward, while the large decay, observed in this case, in the recovery phase of $D_{\text {st }}$ index is connected, in general, to the presence of multiple Interplanetary medium structures, as two MCs, near Earth (Xie et al. 2006). This leaves the necessity of still more study of this event and to analyze many data sets available to try to understand each step along the way from solar source to the effects on the Earth and Earth environment.

\subsection{E-layer dominated ionosphere}

Energetic particles originating from the nighttime magnetosphere are able to ionize the atmosphere significantly in a height range of about $100 \mathrm{~km}$. The penetration depths depend on the energy of the particles. Space-based GNSS radio occultation measurements onboard satellites such as CHAMP, GRACE, and Formosat3/COSMIC are well suited to detect such ionization enhancements in the bottomside ionosphere. So we selected electron density profiles with pronounced ionization at E-Layer height in the range of about $90-150 \mathrm{~km}$ for studying the geophysical conditions under which such enhancements were observed (Mayer \& Jakowski 2009). Solar storms accompanied by coronal mass ejections (CMEs) may enhance precipitation of energetic particles' solar wind energy considerably.

If the electron density in the E-layer is higher as the density in the F2-layer is around $250-350 \mathrm{~km}$, the ionosphere is called an E-layer dominated ionosphere (ELDI) by Mayer \& Jakowski (2009). Analyzing the occurrence probability, these authors show that profiles with enhanced E-layer ionization are closely related to the location and shape of the auroral zone (Fig. 12). Thus, they were able to study the local-time, seasonal, and space-weather dependence of enhanced ionization processes in the auroral zone. The shape of the precipitation region forms an ellipse whose main axis goes through the geomagnetic and geographic poles. Furthermore, one focal point is defined by the geographic pole and the position of the geomagnetic pole is identical with the center point of a circle fit. To evaluate the reliability of radio occultation measurements and to study precipitation processes in more detail, coordinated EISCAT measurements would be useful.

\section{Modeling and forecasting techniques}

The present section describes empirical models of the TEC, the F-layer critical frequency $f o F 2$, and the height of the maximum plasma density. The models use different analytical functions and drivers, but they evaluate the model error in the same way which makes their performance comparable.

In Section 4.1, Andonov et al. (2011) developed an empirical dependence between TEC and the geomagnetic activity described by the $K p$-index. This dependence is expressed as a function of calendar month, geographic latitude, and LT, fitted over a long time series of TEC measurements (October 2004 December 2009) over North America. The authors introduce a modified function of $K p$ obtained by two-dimensional (time-latitude) cross-correlation function, calculated for each month of the year. The modified $K p$ function is defined by two time delay constants for positive and negative TEC deviations respectively.

In Section 4.2, Tsagouri et al. (2009) developed a new ionospheric forecasting algorithm, called the Solar Wind driven autoregression model for Ionospheric short-term Forecast (SWIF). SWIF combines historical and real-time ionospheric observations with solar wind parameters obtained in real time at the L1 point from NASA/ACE spacecraft. SWIF combines the autoregression forecasting algorithm, called Time Series AutoRegressive - TSAR (Koutroumbas et al. 2008), with the empirical Storm Time Ionospheric Model - STIM (Tsagouri \& Belehaki 2006, 2008). Under storm conditions, SWIF adopts progressively the STIM's predictions, while in non-alert conditions, SWIF performs like TSAR.

Section 4.3 describes a model which combines two models developed for different ionospheric conditions. One is the model of the quiet-time behavior of the F-layer peak height $h m F 2$ based on the spherical harmonics analysis technique (Altadill et al. 2009). The other is a model of the storm-time 
variations of $h m F 2$, triggered by IMF Bz (Blanch 2009). The new model provides a near-real time forecasting tool for $h m F 2$ in response to the configuration and variation of the IMF.

The present section includes two other contributions closely connected with to the above topic. The effective sunspot number $-R 12$ eff is used in DIAS (European Digital Upper Atmosphere Server) as a proxy of the ionospheric conditions over Europe for regional ionospheric mapping purposes (Zolesi et al. 2004; Tsagouri et al. 2005). Tsagouri et al. (2009) further studied the efficiency of $R 12$ eff to specify the ionospheric conditions over Europe. The authors show that the deviation of the real-time $R 12 \mathrm{eff}$ estimates from the reference values ( $\Delta R 12 \mathrm{eff})$ follows successfully the ionospheric response to geomagnetic storm enhancements and can be used as a better proxy in specifying the ionospheric state.

Mikhailov et al. (2012) developed a new method for retrieving neutral temperature $\mathrm{Tn}$ and composition [O], $\left[\mathrm{N}_{2}\right],\left[\mathrm{O}_{2}\right]$ from electron density profiles in the daytime mid-latitude F2 region under both quiet and disturbed conditions. The method was tested by using Millstone Hill Incoherent Scatter Radar (ISR) profiles and by co-located Digisonde bottomside profiles complemented with NeQuick topside profiles. Comparison with neutral atmosphere parameters measured by CHAMP satellite shows satisfactory agreement with the model error of order of uncertainty of CHAMP measurements.

\subsection{Empirical model of the TEC response to the geomagnetic activity over the North American region}

This subsection briefly describes an empirical dependence between the TEC and the geomagnetic activity described by the $K p$-index. The detailed description of the model can be seen in Andonov et al. (2011). The wanted dependence is presented as a function of calendar month, geographic latitude, and LT and is obtained by using a long time series of TEC measurements over the region covering North America $\left(50^{\circ} \mathrm{W}-\right.$ $\left.150^{\circ} \mathrm{W}, 10^{\circ} \mathrm{N}-60^{\circ} \mathrm{N}\right)$. The period of time October 2004 December 2009 is considered, therefore, the presented TEC model is valid mainly for low solar activity conditions. The time series of hourly vertical TEC (VTEC) data with latitude/ longitude resolution of $1 \% 1^{\circ}$ are used in this study and the data were downloaded from the NOAA NGDC web site: http:/www.ngdc.noaa.gov/stp/iono/ustec/index.html. The VTEC response to the geomagnetic activity is investigated by considering the relative deviation of VTEC defined as: rVTEC $=$ (VTE$\left.\mathrm{C}_{\text {obs }}-\mathrm{VTEC}_{\text {med }}\right) / \mathrm{VTEC}_{\text {med }}$, where $\mathrm{VTEC}_{\text {med }}$ represents the monthly median value. In this way the regular seasonal, diurnal, and solar changes are removed from the VTEC variability. The data are grouped into 12-month bins with all the available hourly data within the respective month of the year.

As a first step the effect of geomagnetic activity on the rVTEC is studied by cross-correlation analysis. A two-dimensional (time-latitude) cross-correlation function is calculated for each month of the year and the results are shown in Figure 13. The most important feature of the cross-correlation analysis is that for all months the ionospheric response is composed by two phases, positive and negative, with different duration and different time delay. This feature lies at the root of the model, i.e., the impact of the geomagnetic activity on the TEC is accomplished by two mechanisms with different time delay constants that can be described as follows:

$$
r \operatorname{VTEC}(t) \approx\left(f_{\mathrm{TS}}\left(K p_{\mathrm{TS}}(t)\right)+f_{\mathrm{TI}}\left(K p_{\mathrm{TI}}(t)\right) f(\mathrm{LT}),\right.
$$

where $f(\mathrm{LT})$ represents the dependence of the response on LT at equal other conditions, $K p_{\mathrm{Ts}}$ and $K p_{\mathrm{Tl}}$ are the modified $K p$-index with time delay constants respectively $T_{\mathrm{s}}$ and $T_{1}$. The unknown functions $f_{\mathrm{Ts}}$ and $f_{\mathrm{T} 1}$ from (1) are expressed by their Taylor time series expansions while the dependence on LT is represented by a Fourier time series as follows:

$$
\begin{aligned}
f_{\mathrm{TS}}\left(K p_{\mathrm{TS}}\right)= & \alpha_{0 \mathrm{~s}}+ \\
+\ldots, & \alpha_{1 \mathrm{~s}} K p_{\mathrm{TS}}(t)+\alpha_{2 s} K p_{\mathrm{TS}}(t)^{2}+\alpha_{3 \mathrm{~s}} K p_{\mathrm{TS}}(t)^{3} \\
& \ldots \\
f_{\mathrm{TI}}\left(K p_{\mathrm{TI}}\right)= & \alpha_{01}+\alpha_{11} K p_{\mathrm{Tl}}(t)+\alpha_{21} K p_{\mathrm{Tl}}(t)^{2} \\
& +\alpha_{31} K p_{\mathrm{Tl}}(t)^{3}+\ldots, \\
& +2) \\
f_{\mathrm{lt}}(\mathrm{LT})= & \beta_{0}+\sum_{i} \beta_{i} \cos \left(i \frac{2 \pi}{24} L T-\varphi_{i}\right) .
\end{aligned}
$$

It was found also that the functional dependence between $K p$ and rVTEC is close to the cubic function. Then in the Taylor expansion time series (the first two relations in (2) only the first four terms are included. The next step is to obtain the most probable values of the coefficients: $\alpha_{\mathrm{is}}, \beta_{\mathrm{i}}, \alpha_{\mathrm{il}}, T_{\mathrm{s}}$ and $T_{1}$ from (2). This is a nonlinear optimizing task that was solved by searching the minimum RMS error.

In order to demonstrate how the empirical model describes the rTEC, Figure 14 displays the comparison between the rVTEC response from the model (solid line) and observations (dashed line) for two geomagnetic storms in November 2004 (left column of plots) and December 2005 (right column of plots).

The presented method for empirical modeling of the rVTEC response to the geomagnetic activity is able to satisfactorily model the observed responses with similar amplitudes of both positive and negative phases because of the availability of two delayed mechanisms with different time constants. A significant role for improving the model also plays the introduced dependence on LT. The error of the model varies from 0.05 to 0.15 rVTEC units for different months of the year and for different latitudes and longitudes.

\subsection{Advances in the development of ionospheric forecasting models}

The development of a new ionospheric $f_{o} F 2$ forecasting algorithm, called the Solar Wind driven autoregression model for Ionospheric short-term Forecast (SWIF), was recently introduced (Tsagouri et al. 2009).

SWIF combines historical and real-time ionospheric observations with solar wind parameters obtained in real time at the L1 point from NASA/ACE spacecraft. This is achieved through the cooperation of an autoregression forecasting algorithm, called Time Series AutoRegressive - TSAR (Koutroumbas et al. 2008), with the empirical Storm Time Ionospheric Model - STIM (Tsagouri \& Belehaki 2006, 2008) that formulates the ionospheric storm-time response based on solar wind input, exploiting recent advances in ionospheric storm dynamics that correlate the ionospheric storm effects with solar wind parameters (e.g., the magnitude of the IMF and its rate of change as well as the IMF's orientation in the north-south direction). STIM provides a correction factor to the quiet diurnal iono- 
I. Kutiev et al.: Solar activity impact on upper atmosphere

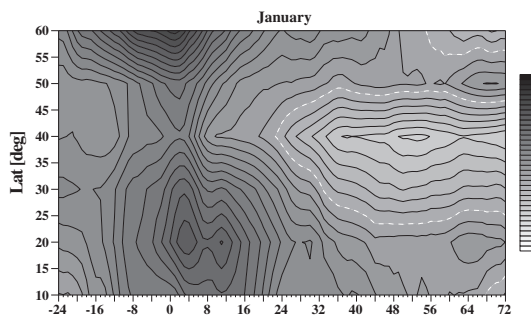

April

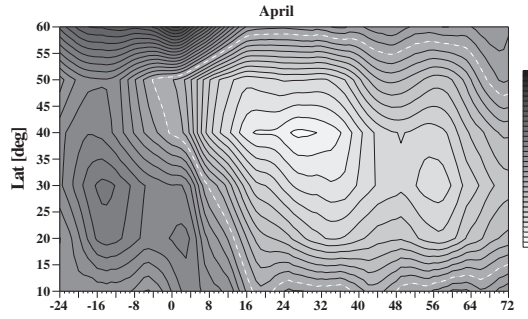

July
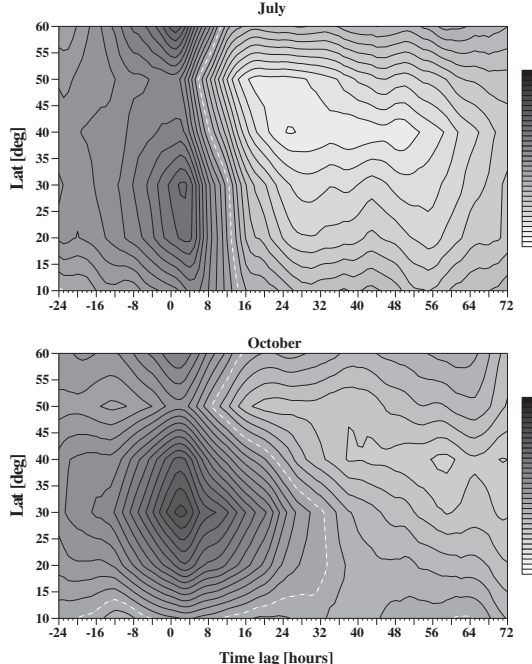

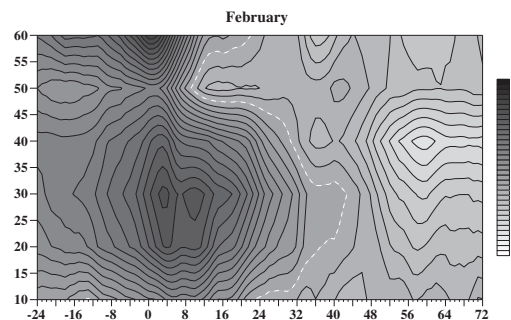

May

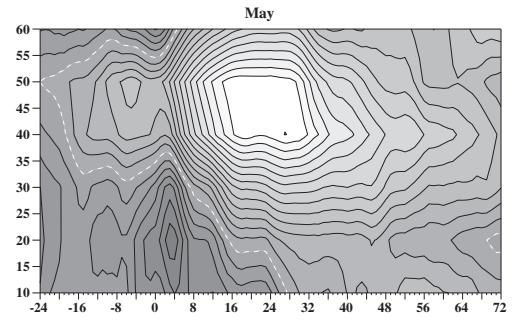

August

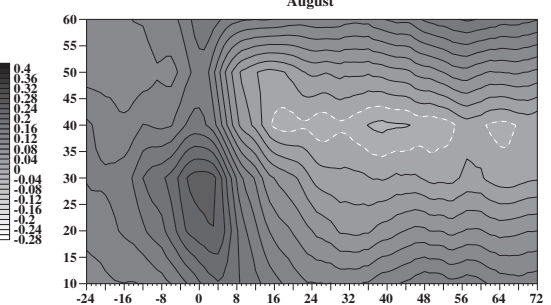

November

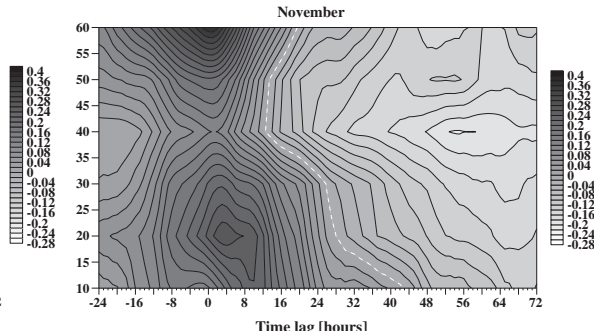

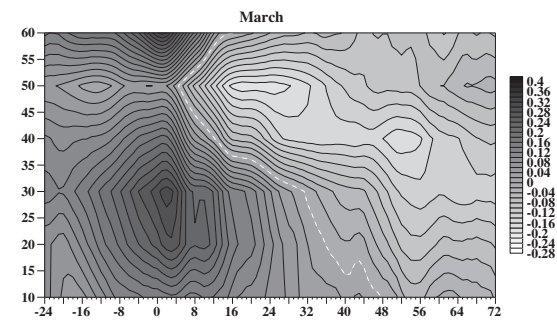

June

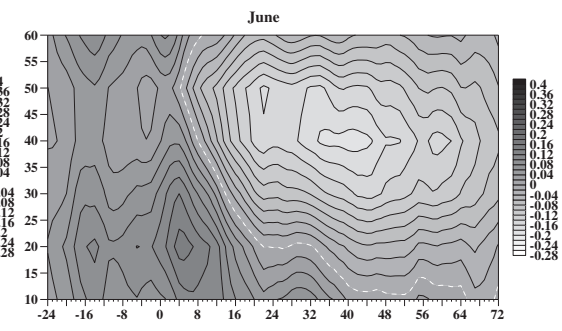

September

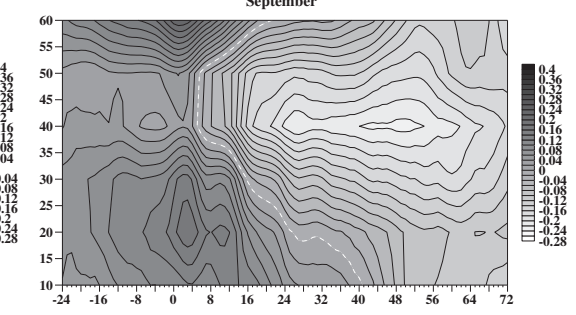

December

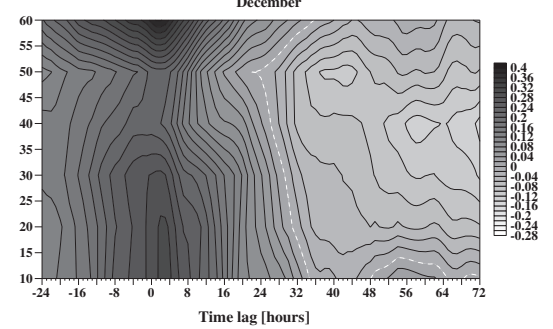

Fig. 13. Two-dimensional (latitude-lag time) cross-correlation functions calculated between the $r \mathrm{VTEC}$ and $K p$-index for 6 months of the year; the zero line is shown by dashed white line (Andonov et al. 2011).

spheric variation during storm conditions, which are determined by monitoring IMF conditions in the Earth's vicinity. It is triggered by an alert signal for upcoming ionospheric disturbances obtained from the online analysis of the IMF's observations obtained from ACE spacecraft. Then, as the ionospheric response evolves and recovers on its own time scales, STIM estimates the time delay in the ionospheric storm onset and formulates the ionospheric storm-time response by taking into account the latitude and the LT of the observation point at the storm onset. SWIF adopts STIM's alert detection algorithm to identify alert conditions for forthcoming ionospheric storm disturbances and to determine the onset time and the duration of the disturbance. Under storm conditions, SWIF adopts the STIM's predictions, while in non-alert conditions, SWIF performs like TSAR. Based on this, SWIF is able to provide alerts and warnings for upcoming ionospheric storm-time disturbances as well as ionospheric forecasts up to $24 \mathrm{~h}$ ahead under all possible conditions.

SWIF's performance was evaluated during disturbed conditions against standard models (e.g., climatology and persistence) and other forecasting models of different philosophy such as the TSAR that is a purely autoregressive technique and the Geomagnetically Correlated Autoregression Model GCAM (Muhtarov et al. 2002) that is driven by the geomagnetic activity level by incorporating the cross-correlation between the $f_{o F} 2$ and the Ap-index into the auto-correlation analysis (Tsagouri et al. 2009). The results verified clear improvement in both quantitative and qualitative terms of SWIF prediction efficiency in respect to TSAR's purely autoregressive approach and comparable performance in respect to the GCAM.

More recently, the performance of both SWIF and GCAM models was systematically evaluated under all possible conditions by carrying out a metrics-based evaluation plan (Tsagouri 2011). This was established on the systematic comparison between models' predictions with actual observations obtained over almost one solar cycle (1998-2007) at four European ionospheric locations (Athens, Chilton, Juliusruh, and Rome) and on the comparison of the models' performance against two standard prediction strategies, the median- and the persistence-based predictions. It was found that both models' prediction accuracy depends on the prediction step, the level of the ionospheric activity, and the latitude of the observation point especially during extremely disturbed conditions. In general, the error tends to be higher for higher prediction steps, higher latitudes, and higher ionospheric activity levels. The models' accuracy in respect to the prediction step was quantified under all levels of ionospheric activity in terms of the mean relative error, MRE that was proven to be free of diurnal and solar cycle dependence. During quiet conditions MRE ranges from $12 \%$ up 

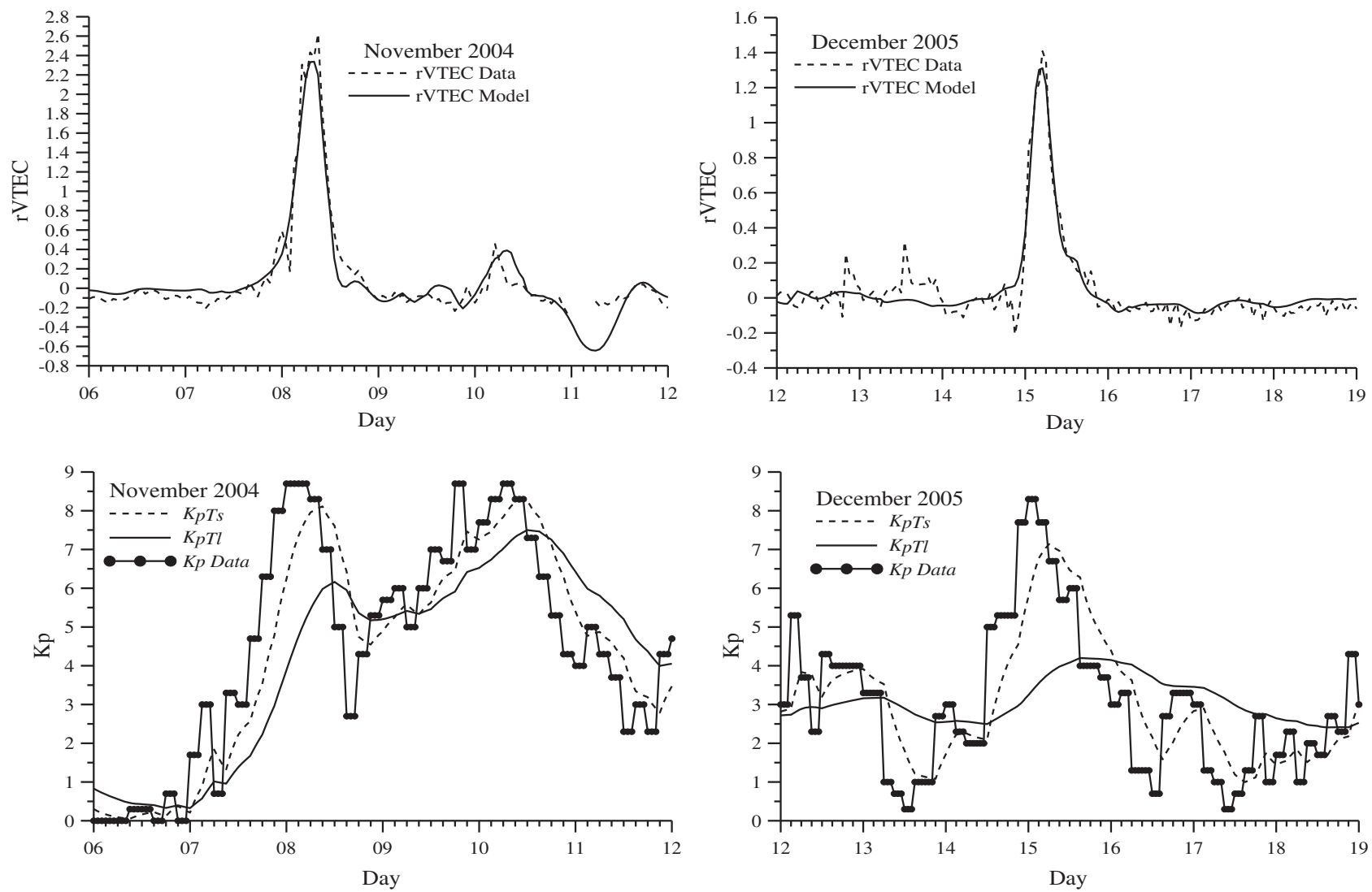

Fig. 14. (Upper row of plots) Comparison between the observed (dashed line) and model (solid line) rVTEC at the geographic point $\left(20^{\circ} \mathrm{N}\right.$, $130^{\circ} \mathrm{W}$ ) for the geomagnetic storm in November 2004 (left plot and December 2005 (right plot); (bottom row of plots) Comparison between the measured $K p$-index (tick solid line with dots) and modified $K p_{\mathrm{Ts}}-$ (dashed line) and $K p_{\mathrm{Tl}}-$ (solid line) indices for November 2004 (left plot) and December 2005 (right plot) (Andonov et al. 2011).
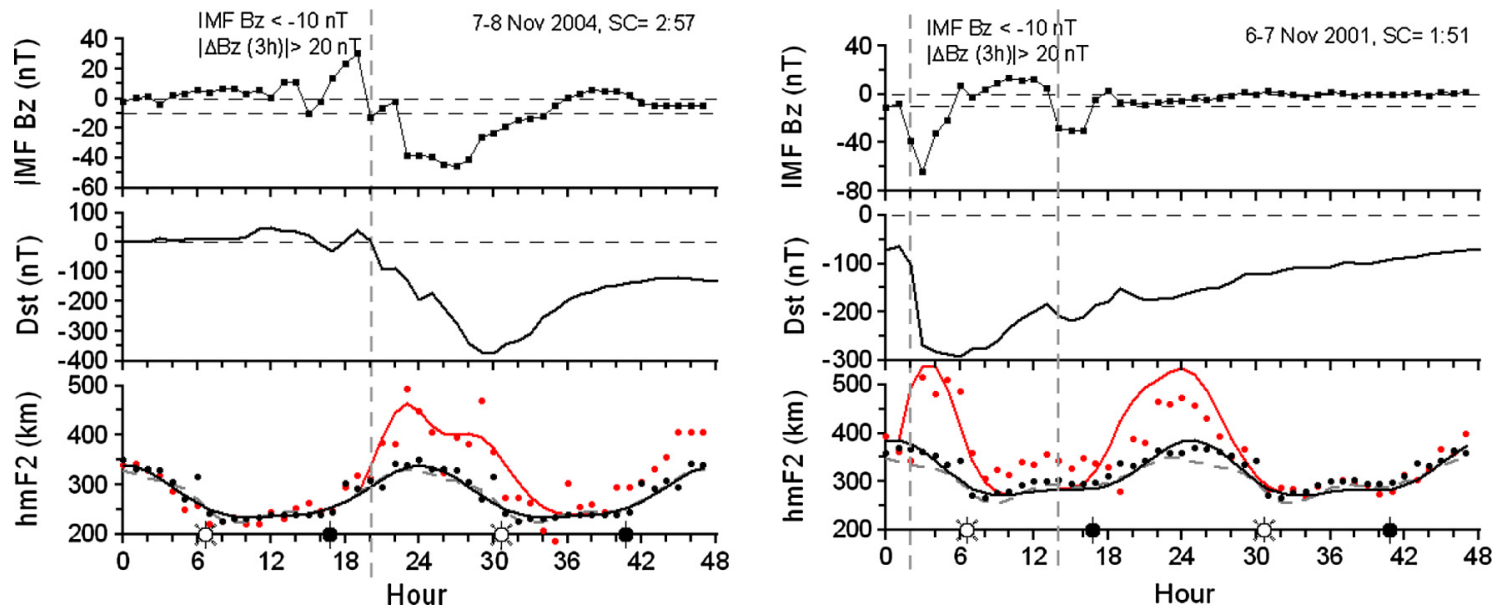

Fig. 15. $h m F 2$ prediction combining both models (red line bottom panel). Red points correspond to experimental values for the corresponding geomagnetic storm. Black points correspond to averaged representative profile data. Black line corresponds to quiet-time $h m F 2$ prediction using the SHA model. Gray dashed line corresponds to IRI-2007 prediction. White sun indicates the sunrise and black sun the sunset. IMF Bz and Dst index are indicated. Vertical gray dashed line indicates the triggering time.

to $15 \%$ for SWIF and from $8 \%$ up to $10 \%$ for GCAM. During disturbed conditions, it is still relatively small (10-13\%) for predictions provided $1 \mathrm{~h}$ ahead and may reach $20 \%$ and $30 \%$ at middle-to-low and middle-to-high latitudes, respectively, for high ionospheric activity level and predictions provided $24 \mathrm{~h}$ ahead.
During quiet and moderately disturbed conditions the two models perform comparable to climatological predictions, expressed by monthly median estimates, and persistence predictions provided either 1 or $24 \mathrm{~h}$ before. During disturbed ionospheric storm conditions considerable improvement (greater than $10 \%$ ) over climatology and persistence is gained for all 
prediction steps and at all latitudes. The averaged improvement over climatology ranges from $30 \%$ to $70 \%$ for GCAM and from $25 \%$ to $70 \%$ for SWIF, giving evidence of the models' efficiency to capture the disturbances, although models' predictions seem to underestimate their intensity. The relative improvement over persistence was investigated separately for storm and post-storm days. It was proved to be significant at almost all cases, ranging from $20 \%$ to $55 \%$ for GCAM and from $10 \%$ to $45 \%$ for SWIF during storm days. The improvement is higher during post-storm days, ranging from $40 \%$ to $60 \%$ for both models. This test verified the models' efficiency to capture the transition from disturbed to quiet conditions.

The evaluation results verified the successful performance of SWIF in alignment with current ionospheric forecasting capabilities. This along with the advantage of SWIF in providing alerts and warnings for forthcoming ionospheric storm disturbances makes SWIF algorithm a powerful tool in the development of a full set of ionospheric forecasting services in operational mode. SWIF is currently implemented online in DIAS system to provide ionospheric forecasts up to $24 \mathrm{~h}$ ahead as well as alerts and warnings for the European region (http://dias.space.noa.gr). In addition, as a clear advance for radio science purposes, it should be noted that SWIF provides an alternative approach to ionospheric forecasting issue, using solar wind parameters as a proxy of the ionospheric activity level. This approach makes SWIF able to adapt new insights potentially available from space weather research and therefore a platform for further investigations/developments.

\subsection{Real-time forecasting tool for $h m F 2$ at midlatitudes combining quiet and disturbance $h m F 2$ models}

The quiet-time behavior of the ionospheric electron density peak height of the $\mathrm{F} 2$ region, $h m F 2$, has been evaluated from average electron density profiles and analytically modeled by the Spherical Harmonic Analysis (SHA) technique following the same methodology as described by Altadill et al. (2009). The SHA model provides a tool to predict $h m F 2$ at any location distributed among the used range of latitudes $\left(70^{\circ} \mathrm{N}-50^{\circ} \mathrm{S}\right)$ and at any time. The SHA model for $h m F 2$ improves the fit to the observed data with respect to IRI prediction, especially at high and low latitudes and they may reduce the deviations by $23 \%$ and $40 \%$, respectively, compared to the deviations of the IRI prediction (Magdaleno et al. 2011).

Studies to determine the typical behavior of the electron density peak height disturbance, $\Delta h m F 2$, at middle latitudes during geomagnetic storms have been performed (Blanch \& Altadill 2012). It has been identified that $h m F 2$ increases systematically $1-3 \mathrm{~h}$ after the geomagnetic storm main phase onset (at the largest change of $D_{\mathrm{st}}$ ) independently of the storm intensity (according to the $D_{\mathrm{st}}$ index) followed by an additional uplift in the nighttime sector. The delay of this second uplift depends on the local time at the main phase onset. Similarly to Saiz et al. (2008), the triggering criteria of the model have been related to the rate of change in the $\mathrm{Bz}$ component of the IMF (an IMF Bz variation of $20 \mathrm{nT}$ in $3 \mathrm{~h}$ ) and to the drop of Bz below $-10 \mathrm{nT}$. The above experimental behavior has been modeled empirically using bell-shaped functions whose coefficients depend on IMF configuration, local time, and season (Eq. (3)).

$$
\Delta h m F 2(t)=A_{1} \times \mathrm{e}^{-\left(t-B_{1}\right)^{2} / C_{1}^{2}}+A_{2} \times \mathrm{e}^{-\left(t-B_{2}\right)^{2} / C_{2}^{2}} .
$$

The obtained empirical model successfully predicts the $\Delta h m F 2$ disturbance in near real time for $86 \%$ of the events with an average RMSE comparable to the expected range of variation for the four quietest days adjacent to the storm event and without false alarms. The experimental behavior supports the storm scenario the traveling atmosphere disturbances (TADs) of auroral origin and changes in the thermospheric wind are the main physical mechanisms driving equatorward-directed and vertical winds which in turn move the plasma along the magnetic field lines and raise the ionospheric peak height. The results of this model have been presented at the COST ES0803 Workshop in Frascati (Blanch \& Altadill 2009a). An extension of this model has been demonstrated to be valid at other European latitudes (Blanch \& Altadill 2009b).

Both models have been combined for better modeling of $h m F 2$ under both quiet and disturbed conditions in order to provide a near-real time forecasting tool for $h m F 2$ in response to the configuration and variation of the interplanetary magnetic field at midlatitudes (Fig. 15). Near real-time data from ACE satellite are used for this purpose. Results show to have a forecast of $h m F 2$ for any conditions some hours in advance when ACE satellite data are available (Saiz et al. 2008).

\subsection{DIAS effective sunspot number: an indicator of the ionospheric activity level over Europe}

DIAS (European Digital Upper Atmosphere Server) effective sunspot number - R12eff was introduced as a proxy of the ionospheric conditions over Europe for regional ionospheric mapping purposes (Zolesi et al. 2004; Tsagouri et al. 2005). Although a pre-processing step for the real-time update of the Simplified Ionospheric Regional Model (SIRMUP) to real-time conditions, $R 12$ eff is available in real time by DIAS system (http://dias.space.noa.gr) for independent use.

Recently, the efficiency of $R 12$ eff in specifying the ionospheric conditions over Europe was further investigated (Tsagouri et al. 2009). For this purpose, the diurnal R12eff's reference pattern was determined on monthly basis and for different solar cycle phases. The deviation of the real-time $R 12$ eff estimates from the reference values, $\Delta R 12$ eff was found to follow successfully the ionospheric response to geomagnetic storm enhancements over Europe. In particular, ionospheric disturbances caused by large-scale phenomena such as the prolonged negative and positive effects observed all over Europe are sufficiently captured in $\Delta R 12 \mathrm{eff}$ variation from the onset of the disturbance until the full recovery (Fig. 16). Limitations are imposed for small-scale effects, such as positive effects of short duration observed locally indicating $\Delta R 12$ eff responses to the averaged ionospheric activity over Europe.

The $\Delta R 12$ eff is negative when negative effects dominate the ionospheric response over Europe and positive during positive ionospheric storm phases. Moreover, there is a clear linear dependence of the average ionospheric storm intensity on $\Delta R 12$ eff magnitude (Fig. 17) that suggests a quantitative relation between them. The above discussion clearly supports the argument that $\Delta R 12 \mathrm{eff}$ and consequently the $R 12 \mathrm{eff}$ itself may be considered as an indicator of the ionospheric activity over Europe.

To conclude, additional work is required in order to fully establish the $R 12$ eff index as an ionospheric activity index for the European region. Future developments may include a more sophisticated method for its derivation in order to anticipate localized ionospheric effects and the quantitative description of its relation to the intensity of ionospheric activity. However, we believe that the results obtained indicate that DIAS effective 


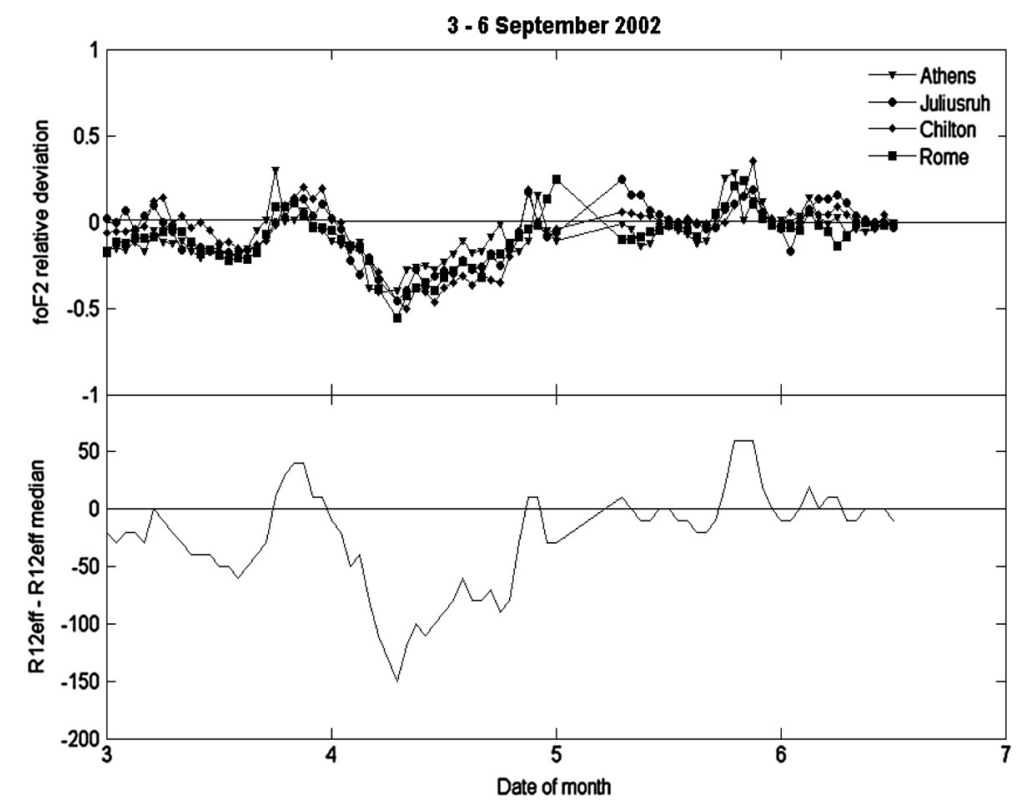

Fig. 16. Top panel: the $f o F 2$ relative deviation from monthly median values $\left(f o F 2\right.$ relative deviation $\left.=\left(f o F 2_{\text {obs }}-f o F 2_{\text {median }}\right) / f o F 2_{\text {median }}\right)$ over several European locations for the storm-time interval 3-6 September 2002. Bottom panel: deviation of $R 12$ eff from $R 12$ eff median (Tsagouri et al. 2009).

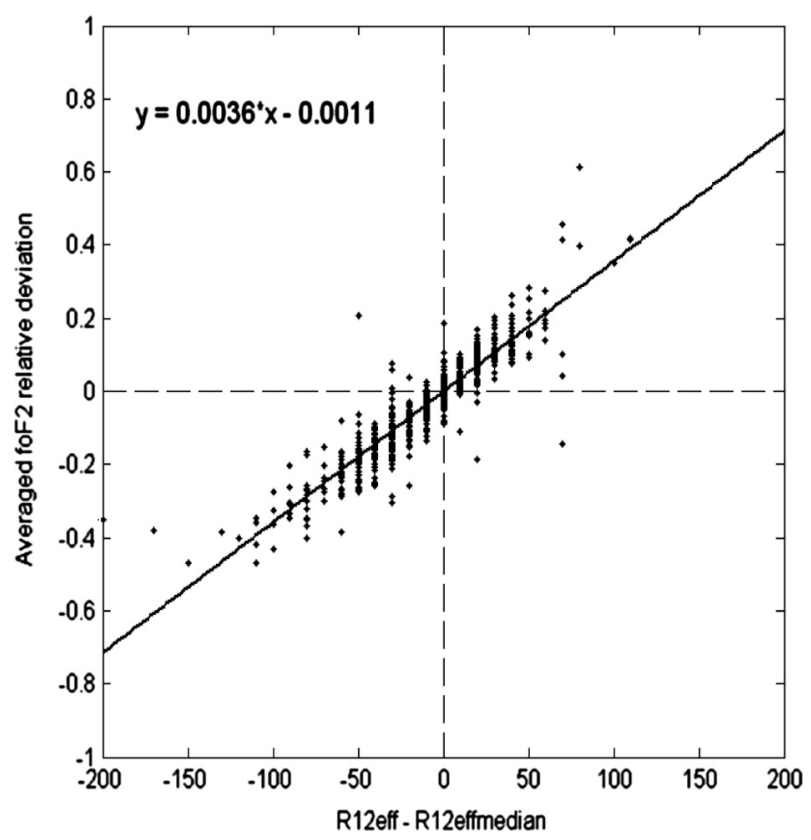

Fig. 17. The averaged relative deviation of $f o F 2$ in respect to median conditions over all DIAS stations versus $\Delta R 12$ eff for 12 storm events (Tsagouri et al. 2009).

sunspot number can provide a reliable estimator of the average ionospheric disturbance level over a substantial part of Europe and a powerful tool for ionospheric specification applications.

\subsection{Retrieval of thermospheric parameters from routine ionospheric observations}

A new method has been developed (Mikhailov et al. 2012) to retrieve neutral temperature $\mathrm{Tn}$ and composition $[\mathrm{O}],\left[\mathrm{N}_{2}\right]$, $\left[\mathrm{O}_{2}\right]$ from electron density profiles in the daytime mid-latitude F2-region under both quiet and disturbed conditions. The new

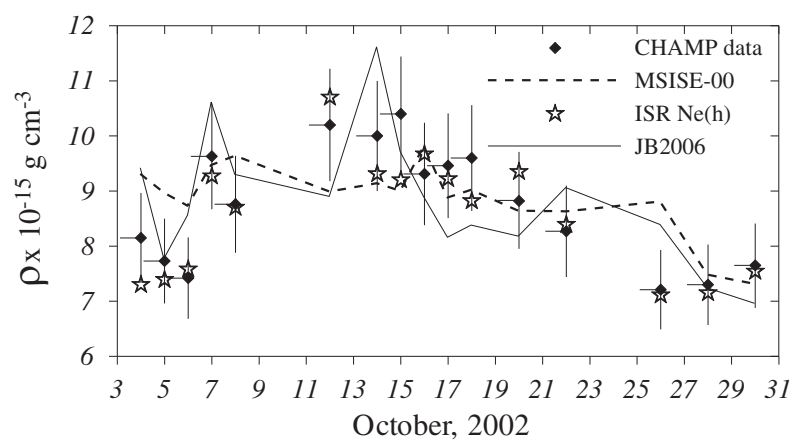

Fig. 18. Reduced to the Millstone Hill location and $400 \mathrm{~km}$ height CHAMP neutral gas density observations along with $\pm 10 \%$ error bars, MSISE-00 and JB2006 model predictions and the model extracted neutral gas density at $400 \mathrm{~km}$ height using ISR $\mathrm{Ne}(\mathrm{h})$ profiles for October 2002 (Mikhailov et al. 2012).

method's performance was also tested through the comparison of the method's predictions with actual measurements and predictions of well-known empirical thermospheric models and the results gave strong evidence for the efficiency of the proposed approach.

Particularly, a comparison with CHAMP neutral gas density observations in the vicinity of Millstone Hill ISR has shown that the retrieved neutral gas densities coincide with the observed ones within the announced accuracy of CHAMP observations, provided that accurate $\mathrm{Ne}(\mathrm{h})$ ISR profiles are used for the retrieval. More precisely, the retrieved gas densities are in the $\pm(10-15) \%$ corridor corresponding to the absolute inaccuracy of CHAMP observations providing accurate $\mathrm{Ne}(\mathrm{h}) \mathrm{ISR}$ profiles which are used for the retrieval (see Fig. 18).

The performance of the method has also been tested ingesting Digisonde $\mathrm{Ne}(\mathrm{h})$ profiles. In this case the agreement with CHAMP neutral gas density observations is less successful (see Fig. 19). Possible factors that can influence the performance accuracy are investigated. These are mostly related to 


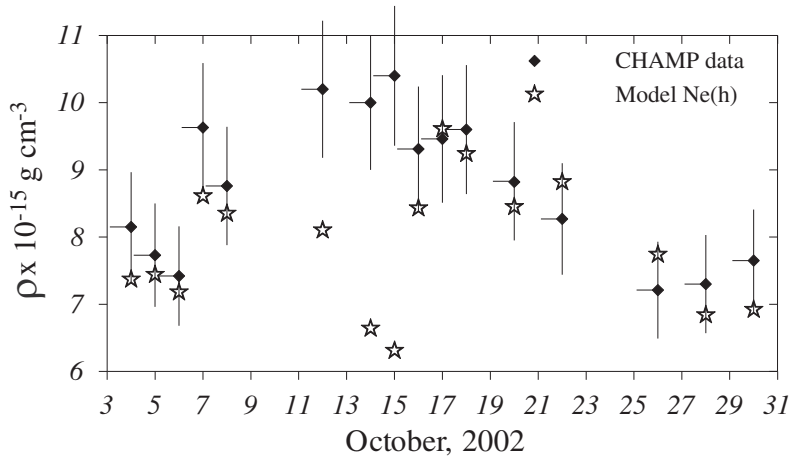

Fig. 19. CHAMP neutral gas density observations, reduced to the location of Millstone Hill, along with $\pm 10 \%$ error bars and the model calculated neutral gas density at $400 \mathrm{~km}$ height using Digisonde/ NeQuick model profiles, for October 2002 (Mikhailov et al. 2012).

limitations due to the ionogram scaling and inversion methods, including performance limitations of the sounding technique itself, like for instance during $G$ conditions. Several tests presented here demonstrate that discrepancies in the $h m F 2$ values provided by the Digisondes could have an important impact on the performance of the method. It should be noted that in all tests performed here using Digisonde $\mathrm{Ne}(\mathrm{h})$ profiles, the topside part is approximated with the NeQuick model.

Despite the limitations related to the use of Digisonde profiles, the proposed method has the potential to monitor the thermosphere at least with ISR $\mathrm{Ne}(\mathrm{h})$ profiles. Digisonde electron density profiles can also be used if quality improvements are made concerning the ionogram inversion methods.

\section{Discussion}

The paper presents results on the reaction of upper atmosphere and ionosphere to solar activity changes, obtained by various research groups in the framework of COST ES0803 Action. There are two main factors, which determine the present, as well as the further development on the subject. First is the availability of quality data, and the second is the utilization of modern and sophisticated mathematical methods for analysis.

The results described in the paper are products on the datadriven analysis. The availability, quality, and coherence of the data are primary factors determining the value of obtained results. The widely used critical frequency of the F-layer $(f o F 2)$ is well-defined parameter extracted from ionograms of ground-based ionosondes. Detailed URSI instructions of ionogram scaling (Piggot \& Rawer 1972) have assured and unified the methodology of manual scaling of $f o F 2$ and allow straightforward compilation of data from various ionosondes worldwide. The modern ionosondes like Digisonde, which use automated scaling software, increase the availability of ionosonde parameters, including true height profiles, but also increase the number of incorrectly scaled parameters. The manual control of the autoscaled parameters is the necessary measure to assure their quality and accuracy of analyses.

The TEC is another useful parameter representing the ionospheric state. The TEC values are mostly derived from GNSS signals and are largely available and easily accessible through the specific web sites. TEC is more robust parameter than $f_{o} F 2$, because it is available even during severe geomagnetic storms, when foF 2 is frequently missing. Whereas groundbased TEC measurements provide valuable information on the horizontal structure of the ionospheric ionization, spacebased GNSS measurements onboard Low Earth Orbiting (LEO) satellites are capable to explore the vertical structure of electron density distribution (Heise et al. 2002; Belehaki et al. 2006). Thus, considering LEO missions such as CHAMP, GRACE, and Formosat3/COSMIC, the radio occultation techniques are already well established to monitor the shape of vertical electron density structure on global scale (Jakowski et al. 2011). The geodetic network is permanently growing. Data gaps over the oceans can be compensated by dual frequency satellite altimetry as demonstrated by TOPEX/Poseidon. Due to the high value of radio occultation measurements for monitoring the current tropospheric weather conditions, a follow on mission of COSMIC/Formosat is planned which will provide a huge database for ionosphere sounding.

The long time series of ionospheric data were of crucial importance for climate change studies. The role of space weather/climate in long-term changes and trends in the upper atmosphere-ionosphere was more important in the past, when it controlled the trends in ionospheric parameters. At present, however, when the dominant controlling parameter seems to be increasing concentration of $\mathrm{CO}_{2}$, monitoring of tropospheric constituents and especially the trace gases has become of primary importance (Lastovicka et al. 2012). Concerning space weather, future studies should focus on analysis of the long-lasting and very deep solar cycle minimum and related very low level of geomagnetic activity in order to estimate its influence on long-term trends in the ionosphere, particularly on future trends, as we can expect weak solar cycles in the coming decades.

Various methods for data analysis are continuously being improved and adopted for specific applications. The methods underwent significant development being using spectral analysis. Concerning the results in this paper, the power spectra of ionospheric parameters are presented in the form of amplitude wavelet spectra. Oscillations with periods of 5-30 days are transient phenomena that are most effectively identified by a wavelet transform method. The wavelet analysis presented here employs the continuous Morlet wavelet, which consists of a cosine wave modulated by a Gaussian envelope. The nondimensional frequency, which gives the number of oscillations within the wavelet itself, is set to six to satisfy the wavelet admissibility condition (Torrence \& Compo 1998). The main advantage of wavelet analysis comes from its frequency/time maps, which visualize oscillation amplitudes and allow comparison between various drivers and ionospheric parameters. The simple interpretation of the periodic variations makes the wavelet analysis attractive for increasing number of ionospheric researchers.

Empirical ionospheric models are most suitable for application-oriented research and operational services, like ionospheric forecasting. While all models are based on the linear regression approach, the correct relation between drivers and response parameters is still a state-of-art solution. The main advancement of contemporary models is the introduction of delayed reaction of ionosphere to the driver forcing. All forecasting models presented in the paper include time delay functions. This is especially important when using geomagnetic indices and solar wind parameters as drivers. At equal other conditions, a proper time delayed reaction can increase significantly the accuracy of model and its predictions. This is one of the main lines of improvement of forecasting technique.

Acknowledgements. The results presented in this paper were obtained within the frame of COST ES0803 Action. 


\section{References}

Altadill, D., and E.M. Apostolov, Time and scale size of planetary wave signatures in the ionospheric $\mathrm{F}$ region: Role of the geomagnetic activity and mesosphere/lower thermosphere wind, J. Geophys. Res., 108, 1403, DOI: 10.1029/2003JA010015, 2003.

Altadill, D., E.M. Apostolov, J.G. Sole, and Ch. Jacobi, Origin and development of vertical propagating oscillations with periods of planetary waves in the ionospheric F region, Phys. Chem. Earth Part C, 26, 387-393, 2001.

Altadill, D., J.M. Torta, and E. Blanch, Proposal of new models of the bottom-side B0 and B1 parameters for IRI, Adv. Space Res., 43, 1825-1834, 2009.

Andonov, B., P. Mukhtarov, and D. Pancheva, Empirical model of the TEC response to the geomagnetic activity over the North American region, Adv. Space Res., 48, 1041-1048, DOI: 10.1016/j.asr.2011.05.007, 2011.

Araujo-Pradere, E.A., T.J. Fuller-Rowell, and M.V. Codrescu, STORM: an empirical storm-time ionospheric correction model, 1, Model description, Radio Sci., 37, 5, 1070, DOI: 10.1029/2001RS002467, 2002.

Bartels, J., Twenty-seven day recurrences in terrestrial-magnetic and solar activity, 1923-1933, Terr. Magn. Atmos. Electr., 39 (3), 201-202, DOI: 10.1029/TE039i003p00201, 1934.

Belehaki, A., P. Marinov, I. Kutiev, N. Jakowski, and S.M. Stankov, Comparison of the topside ionosphere scale height determined by topside sounders model and bottomside digisonde profiles, $A d v$. Space Res., 37, 963-966, 2006.

Bilitza, D., International reference ionosphere 2000, Radio Science, 36 (2), 261-275, 2000.

Blanch, E., Typical behaviour of the ionospheric vertical structure during quiet and disturbed conditions, Doctoral Thesis, Univ. Ramon Llull, Barcelona, Spain, 2009.

Blanch, E., and D. Altadill, Ionospheric peak height density disturbance in response to solar wind conditions: a potential empirical model, Paper presented at the COST ES0803 Workshop, 1-3 April, Frascati, Italy, 2009a.

Blanch, E., and D. Altadill, Empirical model for the electron density peak height disturbance in response to solar wind conditions, Paper presented at the 6th General Assembly of the European Geosciences Union, Session ST12, EGU2009- 4568, Vienna, Austria, 19-24 April, 2009b.

Blanch, E., and D. Altadill, Mid-latitude F-region peak height changes in response to interplanetary magnetic field conditions and modeling results, J. Geophys. Res., 117, A12, DOI: 10.1029/2012JA018009, 2012.

Borovsky, J.E., and M.H. Denton, Differences between CME-driven storms and CIR-driven storms, J. Geophys. Res., 111, A07S08, DOI: 10.1029/2005JA011447, 2006.

Bremer, J., J. Laštovička, A.V. Mikhailov, D. Altadill, P. Bencze, D. Burešová, G. De Franceschi, C. Jacobi, S. Kouris, L. Perrone, and E. Turunen, Climate of the upper atmosphere, Ann. Geophys., 52 (3/4), 273-299, 2009.

Dasso, S., C.H. Mandrini, B. Schmieder, H. Cremades, C. Cid, et al., Linking two consecutive nonmerging magnetic clouds with their solar sources, J. Geophys. Res., 114, A2, DOI: 10.1029/2008JA013102, 2009.

Denton, M.H., T. Ulich, and E. Turunen, Modification of midlatitude ionospheric parameters in the F2 layer by persistent high-speed solar wind streams, Space Weather, 7, S04006, DOI: 10.1029/2008SW000443, 2009.

Emmert, J.T., J.M. Picone, and R.R. Meier, Thermospheric global average density trends 1967-2007, derived from orbits of 5000 near-Earth objects, Geophys. Res. Lett., 35, L05101, DOI: 10.1029/2007GL032809, 2008.

Hall, C.M., K. Rypdal, and M. Rypdal, The E region at $69^{\circ} \mathrm{N}$, $19^{\circ} \mathrm{E}$ : trends, significances, and detectability, J. Geophys. Res., 116, A05309, DOI: 10.1029/2011JA016431, 2011.

Heise, S., N. Jakowski, A. Wehrenpfennig, Ch. Reigber, and H. Luehr, Sounding of the topside ionosphere/plasmasphere based on
GPS measurements from CHAMP: initial results, Geophys. Res. Lett., 29 (14), DOI: 10.1029/2002GL014738, 2002.

Jakowski, N., TEC monitoring by using satellite positioning systems, in Modern Ionospheric Science, edited by H. Kohl, R. Rüster, and K. Schlegel, EGS, Katlenburg-Lindau, ProduServ GmbH Verlagsservice, Berlin, pp. 371-390, 1996.

Jakowski, N., B. Fichtelmann, and A. Jungstand, Solar activity control of ionospheric and thermospheric processes, J. Atmos. Terr. Phys., 53, 1125-1130, 1991.

Jakowski, N., J. Mielich, C. Borries, L. Cander, A. Krankowski, B. Nava, and S.M. Stankov, Large scale ionospheric gradients over Europe observed in October 2003, J. Atmos. Sol. Terr. Phys., 70, 15, DOI: 10.1016/j.jastp.2008.03.020, 2008.

Jakowski, N., C. Mayer, M.M. Hoque, and V. Wilken, TEC models and their use in ionosphere monitoring, Radio Sci., 46, RS0D18, DOI: 10.1029/2010RS004620, 2011.

Koutroumbas, K., I. Tsagouri, and A. Belehaki, Time series autoregression technique implemented on-line in DIAS system for ionospheric forecast over Europe, Ann. Geophys., 26 (2), $371-$ 386, 2008.

Kutiev, I., S. Watanabe, Y. Otsuka, and A. Saito, Total electron content behavior over Japan during geomagnetic storms, J. Geophys. Res., 110 (A1), A01308, DOI: 10.1029/2004JA010586, 2005.

Kutiev, I., Y. Otsuka, D. Pancheva, and R. Heelis, Response of lowlatitude ionosphere to medium-term changes of solar and geomagnetic activity, J. Geophys. Res., 117, A08330, DOI: 10.1029/2012JA017641, 2012

Lastovicka, J., Global pattern of trends in the upper atmosphere and ionosphere: recent progress, J. Atmos. Solar Terr. Phys., 71 (14-15), 1514-1528, 2009.

Lastovicka, J., R.A. Akmaev, G. Beig, J. Bremer, and J.T. Emmert, Global change in the upper atmosphere, Science, 314, 1253-1254, DOI: 10.1126/science.1135134, 2006.

Lastovicka, J., S.C. Solomon, and L. Qian, Trends in the neutral and ionized upper atmosphere, Space Sci. Rev., 168, 113-145, DOI: 10.1007/s11214-011-9799-3, 2012.

Lean, J.L., H.P. Warren, J.T. Mariska, and J. Bishop, A new model of solar EUV irradiance variability 2. Comparisons with empirical models and observations and implications for space weather, $J$. Geophys. Res., 108 (A2), 1059, DOI: 10.1029/2001JA009238, 2003.

Lei, J., J.P. Thayer, J.M. Forbes, E.K. Sutton, and R.S. Nerem, Rotating solar coronal holes and periodic modulation of the upper atmosphere. Geophys. Res. Lett., 35, L10109, DOI: 10.1029/2008GL033875, 2008.

Magdaleno, S., D. Altadill, M. Herraiz, E. Blanch, and B. de la Morena, Ionospheric peak height behaviour for low, middle and high latitudes, A potential empirical model for quiet conditions Comparison with the IRI-2007 model, J. Atmos. Sol. Terr. Phys., 73 (13), 1810-1817, DOI: 10.1016/j.jastp.2011.04.019, 2011.

Mayer, C., and N. Jakowski, Enhanced E layer ionization in the auroral zones observed by radio occultation measurements onboard CHAMP and Formosat-3/COSMIC, Ann. Geophys., 27, 1207-1212, 2009.

Mayer, C., B. Belabbas, N. Jakowski, M. Meurer, and W. Dunkel, Ionosphere threat space model assessment for GBAS, Proc. ION GNSS 2009, Savannah, GA, USA, 22-25 September, 2009.

Maunder, W.E., Magnetic disturbances, 1882 to 1903 , as recorded at the Royal Observatory, Greenwich, and their association withsunspots, Mon. Not. R. Astron. Soc., 65 (1), 2-34, 1904.

Mikhailov, A.V., A. Belehaki, L. Perrone, B. Zolesi, and I. Tsagouri, Retrieval of thermospheric parameters from routine ionospheric observations: assessment of method's performance at midlatitudes daytime hours, J. Space Weather Space Clim., 2, A03, DOI: 10.1051/swsc/2012002, 2012.

Mlynczak, M.G., F.J. Martin-Torres, C.J. Mertens, B.T. Marshall, R.E. Thompson, J.U. Kozyra, E.E. Remsberg, L.L. Gordley, J.M. RusselIII, and T. Woods, Solar-terrestrial coupling evidenced by periodic behavior in geomagnetic indexes and the infrared energy budget of the thermosphere, Geophys. Res. Lett., 35, L05808, 2008. 


\section{Kutiev et al.: Solar activity impact on upper atmosphere}

Mlynczak, M., L. Hunt, B.T. Marshall, F.J. Martin-Torres, C.J. Mertens, et al., Observations of infrared radiative cooling in the thermosphere on daily to multiyear timescales from the TIMED/ SABER instrument, J. Geophys. Res., 115, A03309, DOI: 10.1029/2009JA014713, 2010.

Muhtarov, P., I. Kutiev, and L.R. Cander, Geomagnetically correlated autoregression model for short-term prediction of ionopsheric parameters, Inverse Prob., 18, 49-65, 2002.

Mukhtarov, P., and D. Pancheva, Thermosphere-ionosphere coupling in response to recurrent geomagnetic activity, J. Atmos. Sol. Terr. Phys., 74, 132-145, DOI: 10.1016/j.jastp.2012.02.013, 2012.

Mursula, K., and D. Martini, Centennial increase in geomagnetic activity: Latitudinal difference and global estimates, J. Geophys. Res., 111, A08209, DOI: 10.1029/2005JA011549, 2006.

Pancheva, D., and P. Mukhtarov, Wavelet analysis on transient behaviour of tidal amplitude fluctuations observed by meteor radar in the lower thermosphere above Bulgaria, Ann. Geophys., 18, 316-333, 2000.

Pancheva, D., N. Mitchell, R.R. Clark, J. Drobjeva, and J. Lastovicka, Variability in the maximum height of the ionospheric F2-layer over Millstone Hill (September 1998-March 2000); influence from below and above, Ann. Geophys., 20, 1807-1819, 2002.

Perrone, L., L. Alfonsi, V. Romano, and G. De Franceschi, Polar cap absorption events of Novembre 2001 at Terra Nova Bay, Antartica, Ann. Geophys., 22, 1633-1648, 2004.

Perrone, L., M. Parisi, A. Meloni, M. Damasso, and M. Galliani, Study on solar sources and polar cap absorption events recorded in Antarctica, Adv. Space Res., 43 (11), 1660-1668, 2009.

Piggot, W.R., and K. Rawer, URSI Handbook of Ionograms Interpretation and Reduction, 2nd edn. report UAG-23A, WDC-A for STP, Boulder, Co, 1972.

Qian, L., S.C. Solomon, R.G. Roble, and T.J. Kane, Model simulations of global change in the ionosphere, Geophys. Res. Lett., 35, L07811, DOI: 10.1029/2007GL033156, (2008).

Qian, L., J. Lastovicka, R.G. Roble, and S.C. Solomon, Progress in observations and simulations of global change in the upper atmosphere, J. Geophys. Res., 116 (A4), A00H03, DOI: 10.1029/2010JA016317, 2011.

Reinisch, B.W. and X. Huang, Automatic calculation of electron density profiles from digital ionoograms 3. Processing of bottomside ionograms, Radio Sci., 18 (3), 477-492, DOI: 10.1029/RS18i003p00477, 1983.

Saiz, E., C. Cid, and Y. Cerrato, Forecasting intense geomagnetic activity using interplanetary magnetic field data, Ann. Geophys., 26, 3989-3998, 2008.

Solomon, S.C., T.N. Woods, L.V. Didkovsky, J.T. Emmert, and L. Qian, Anomalously low solar extreme-ultraviolet irradiance and thermospheric density during solar minimum, Geophys. Res. Lett., 37, L16103, DOI: 10.1029/2010GL044468, 2010.

Temmer, M., B. Vršnak, and A.M. Veronig, Periodic appearance of coronal holes and the related variation of solar wind parameters, Sol. Phys., 241, 371-383, DOI: 10.1007/s11207-007-0336-1, 2007.

Thayer, J.P., J. Lei, J.M. Forbes, E.K. Sutton, and R.S. Nerem, Thermospheric density oscillations due to periodic solar wind high-speed streams, J. Geophys. Res., 113, A06307, DOI: 10.1029/2008JA013190, 2008.

Torrence, C., and G. Compo, A practical guide to wavelet analysis, Bull. Am. Meteorol. Soc., 79, 61-78, 1998.

Tsagouri, I., B. Zolesi, A. Belehaki, and L.R. Cander, Evaluation of the performance of the real-time updated simplified ionospheric regional model for the European area, J. Atmos. Sol.-Terr. Phys., 67 (12), 1137-1146, DOI: 10.1016/j.jastp.2005.01.012, 2005.

Tsagouri, I., Evaluation of the performance of DIAS ionospheric forecasting models, J. Space Weather Space Space Clim., 1, A02, DOI: 10.1051/swsc/2011110003, 2011.

Tsagouri, I., and A. Belehaki, "A new empirical model of middle latitude ionospheric response for space weather applications, $A d v$. Space Res., 37 (2), 420-425, 2006.

Tsagouri, I., and A. Belehaki, An upgrade of the solar-wind-driven empirical model for the middle latitude ionospheric storm-time response, J. Atmos. Sol. Terr. Phys., 70 (16), 2061-2076, 2008.

Tsagouri, I., B. Zolesi, R. Cander Lj, and A. Belehaki, DIAS effective sunspot number as an indicator of the ionospheric activity level over Europe, Acta Geophys., DOI: 10.2478/s11600-009-0045-2, 2009

Tsurutani, B., W. Gonzalez, A. Gonzalez, A.L.C. Gonzalez, F. Guarnieri, et al., Corotating solar wind streams and recurrent geomagnetic: a review, J. Geophys. Res., 111, A07S01, DOI: 10.1029/2005JA011273, 2006.

Vršnak, B., M. Temmer, and A.M. Veroning, Coronal holes and solar with high-speed streams: I. Forecasting the solar wind parameters, Sol. Phys., 240, 315-330, 2007.

Xie, H.N., N. Gopalswamy, P.K. Manoharan, A. Lara, S. Yashiro, and S. Lepri, Long-lived geomagnetic storms and corononal mass ejections, J. Geophys. Res, 111, A1, DOI: 10.10129/2005JA011287, 2006.

Zolesi, B., A. Belehaki, I. Tsagouri, and L.R. Cander, Real-time updating of the simplified ionospheric regional model for operational applications, Radio Sci., 39, RS2011, DOI: 10.1029/2003RS002936, 2004.

Zhang, J., I.G. Richardson, D.F. Webb, N. Gopalswamy, E. Huttunen, Correction to Solar and interplanetary sources of major geomagnetic storms (Dst $\leq-1000 \mathrm{nT})$ during 1996-2005, J. Geophys. Res, 112, DOI: 10.10129/2007JA012891, 2007.

Cite this article as: Kutiev I, Tsagouri I, Perrone L, Pancheva D, Mukhtarov P, Mikhailov A, Lastovicka J, Jakowski N, Buresova D, Blanch E, Andonov B, Altadill D, Magdaleno S, Parisi M \& Miquel Torta J: Solar activity impact on the Earth's upper atmosphere. J. Space Weather Space Clim., 2013, 3, A06. 